NBER WORKING PAPER SERIES

ON THE ASSET MARKET VIEW OF EXCHANGE RATES

\author{
A. Craig Burnside \\ Jeremy J. Graveline \\ Working Paper 18646 \\ http://www.nber.org/papers/w18646 \\ NATIONAL BUREAU OF ECONOMIC RESEARCH \\ 1050 Massachusetts Avenue \\ Cambridge, MA 02138 \\ December 2012, Revised January 2019
}

Previous versions of this paper were entitled "Exchange Rates and International Risk Sharing" and "Exchange Rate Determination, Risk Sharing, and the Asset Market View." We thank three anonymous referees, Hengjie Ai, Andrew Ang, Snehal Banerjee, Martin Bodenstein, John Cochrane, Bernard Dumas, Martin Eichenbaum, Martin Evans, Nir Jaimovich, Jonathan Parker, Uday Rajan, Sergio Rebelo, Lucio Sarno, Raj Singh, Gabriel Talmain, Giorgio Valente, Jules Van Binsbergen, seminar participants at Cass Business School, Duke University, Essex Business School, the Federal Reserve Board, and the University of Michigan, and conference participants at Northwestern University, the University of Glasgow, the University of Minnesota, Oxford University, the Chicago Fed, Queen's University, the American Finance Association meetings in San Diego, the NBER Summer Institute Asset Pricing meeting, and the NBER International Finance and Macroeconomics meeting for helpful comments and conversations. Any errors or omissions are our own. The views expressed herein are those of the authors and do not necessarily reflect the views of the National Bureau of Economic Research.

NBER working papers are circulated for discussion and comment purposes. They have not been peer-reviewed or been subject to the review by the NBER Board of Directors that accompanies official NBER publications.

(C) 2012 by A. Craig Burnside and Jeremy J. Graveline. All rights reserved. Short sections of text, not to exceed two paragraphs, may be quoted without explicit permission provided that full credit, including $\odot$ notice, is given to the source. 
On the Asset Market View of Exchange Rates

A. Craig Burnside and Jeremy J. Graveline

NBER Working Paper No. 18646

December 2012, Revised January 2019

JEL No. F31,G15

\title{
ABSTRACT
}

If the asset market is complete then the difference between foreign and domestic agents' log intertemporal marginal rates of substitution (IMRSs) equals the log change in the real exchange rate. This equation is frequently used to argue that changes in real exchange rates reflect differences between agents' required compensation for exposure to asset return uncertainty. We show that the relative returns on frictionlessly traded assets are only reflected in the common component of agents' IMRSs, not differences. Instead, when this equation does offer insights, frictions in the goods market are the source of economic distinction between agents.

\author{
A. Craig Burnside \\ Department of Economics \\ Duke University \\ 213 Social Sciences Building \\ Durham, NC 27708-0097 \\ and NBER \\ craig.burnside@duke.edu \\ Jeremy J. Graveline \\ Pluribus Labs LLC \\ San Francisco, CA \\ jjgraveline@gmail.com
}


If the asset market is complete then the log change in the real exchange rate equals the difference between foreign and domestic agents' log intertemporal marginal rates of substitution (IMRSs):

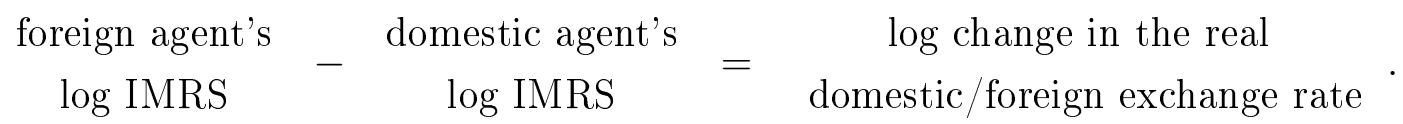

Brandt, Cochrane, and Santa-Clara (2006) refer to Eq. (1) as the asset market view of exchange rates. ${ }^{1}$ It is now a dominant theoretical framework in the recent international asset pricing literature and has been used to understand exchange rate determination, foreign exchange risk premia, and international risk sharing. ${ }^{2}$ For a recent survey of this literature, see Lustig and Verdelhan (2012).

We offer a critique of this framework. The difference between agents' log IMRSs is often interpreted as the difference between their required compensation for exposure to the uncertainty in asset returns. However, this economic interpretation does not account for any difference in units over which agents' IMRSs are expressed. When Eq. (1) holds, we show that the foreign and domestic agents actually require the same, not different, compensation for exposure to asset return uncertainty.

Therefore, structural assumptions about preferences and goods market frictions are necessary to interpret variation in real exchange rates as differences between agents' IMRSs. For example, suppose that the asset market is complete and agents in different economies have the same consumption aggregators over individual goods. With these assumptions, frictions in the goods market are the only source of economic distinction between agents, and the amount of variation in the real exchange rate reflects the degree to which this risk in the goods market is not shared across these economies. However, there is an important observational equivalence problem. We show that the same real exchange rate behavior can result if the asset market is complete and goods markets are frictionless, but agents have different preferences over individual goods. In this case, agents share risk perfectly. Thus, armed

\footnotetext{
${ }^{1}$ In a distinct earlier literature, the "asset market view of exchange rates" referred to the role of asset markets and capital mobility in exchange rate determination. This literature emphasized the importance of the fact that nominal exchange rates and asset markets adjust much more quickly than goods markets. See, for example, Dornbusch (1976), Frenkel (1976), Kouri (1976), and Mussa (1976).

${ }^{2}$ Examples of papers where this approach appears include: Bansal (1997); Backus, Foresi, and Telmer (2001); Brandt and Santa-Clara (2002); Smith and Wickens (2002); Ahn (2004); Brandt, Cochrane, and Santa-Clara (2006); Lustig and Verdelhan (2006); Brennan and Xia (2006); Lustig and Verdelhan (2007); Bakshi, Carr, and Wu (2008); Verdelhan (2010); Colacito and Croce (2011); Lustig, Roussanov, and Verdelhan (2011); Bansal and Shaliastovich (2013); and Lustig, Roussanov, and Verdelhan (2014).
} 
only with asset returns, exchange rates, and aggregate consumption data, it is impossible to differentiate between models in which agents share risk perfectly and ones where they don't. Although our paper is a critique, a positive message from it is that structural modeling is helpful if it is specific about goods markets and preferences over disaggregated consumption, and brings relevant evidence to bear.

\section{The Asset Market View of Exchange Rates}

To facilitate comparisons across economies, consider a frictionlessly traded basket of assets and/or goods and services that serves as a common numeraire. In the domestic economy, let $P_{d, t}$ be the number of units of this numeraire that can be traded for one unit of the domestic representative agent's consumption basket of goods and services at time $t$. Likewise, let $P_{f, t}$ be the number of numeraire units that can be traded for one unit of the foreign agent's consumption basket at time $t$ in the foreign economy.

The real domestic/foreign exchange rate, $e_{t}=P_{f, t} / P_{d, t}$, is the price of a unit of the foreign agent's consumption basket, expressed in units of the domestic agent's consumption basket. Any frictionlessly traded numeraire yields the same real exchange rate. Let $X_{t}$ be the gross change in the real exchange rate from time $t-1$ to $t$. Then,

$$
X_{t}=e_{t} / e_{t-1}=\delta_{d, t} / \delta_{f, t}, \quad \text { where } \quad \delta_{d, t}=P_{d, t-1} / P_{d, t} \quad \text { and } \quad \delta_{f, t}=P_{f, t-1} / P_{f, t} .
$$

The real exchange rate is constant if the composition of agents' consumption baskets is identical, and they face the same prices for all goods and services (i.e., purchasing power

parity holds across these economies). Therefore, the real exchange rate only varies over time if at least one of these conditions is violated.

Consider an arbitrage-free set of $k$ assets that can be frictionlessly traded across these economies. Let $\boldsymbol{R}_{t}^{\eta}$ denote the vector of gross returns on these assets, from time $t-1$ to $t$, denominated in units of our numeraire. Then the gross asset returns, denominated in units of the domestic and foreign agents' consumption baskets, are given by

$$
\boldsymbol{R}_{t}=\delta_{d, t} \boldsymbol{R}_{t}^{\eta} \quad \text { and } \quad \boldsymbol{R}_{t}^{*}=\delta_{f, t} \boldsymbol{R}_{t}^{\eta}
$$

respectively.

For concreteness (and without loss of generality), a portfolio of the assets themselves can serve as our common numeraire, so long as its gross return is almost surely strictly positive. 
Let $\boldsymbol{\eta}$ be a vector of portfolio weights for such a numeraire, in which case $\boldsymbol{R}_{t}^{\eta}$ is the vector of gross asset returns relative to the gross return on this portfolio. Then $\delta_{d, t}$ and $\delta_{f, t}$ equal the gross return on this numeraire portfolio, denominated in units of the domestic and foreign consumption baskets, respectively. That is,

$$
\boldsymbol{R}_{t} \cdot \boldsymbol{\eta}=\delta_{d, t}, \quad \boldsymbol{R}_{t}^{*} \cdot \boldsymbol{\eta}=\delta_{f, t}, \quad \text { and } \quad \frac{\boldsymbol{R}_{t}}{\boldsymbol{R}_{t} \cdot \boldsymbol{\eta}}=\boldsymbol{R}_{t}^{\eta}=\frac{\boldsymbol{R}_{t}^{*}}{\boldsymbol{R}_{t}^{*} \cdot \boldsymbol{\eta}}
$$

where $\boldsymbol{a} \cdot \boldsymbol{b}$ denotes the dot product of vectors $\boldsymbol{a}$ and $\boldsymbol{b}$.

Let $M_{d, t}$ be the domestic agent's IMRS, between time $t-1$ and $t$, expressed over units of her consumption basket of goods and services. Likewise, let $M_{f, t}^{*}$ be the foreign agent's IMRS over units of his consumption basket during this period. Since the agents can trade the assets, their IMRSs must satisfy the well-known first order (Euler) conditions

$$
\mathbb{E}\left[M_{d, t} \boldsymbol{R}_{t}\right]=\mathbf{1}=\mathbb{E}\left[M_{f, t}^{*} \boldsymbol{R}_{t}^{*}\right]
$$

In Eq. (5), 1 is a vector of 1's and $\mathbb{E}[\cdot]$ denotes expectation conditional on information available at time $t-1$ (for notational convenience, we drop the explicit dependence on the time $t-1$ information set).

When expressed over units of our common numeraire, the agents' IMRSs must equal

$$
M_{d, t}^{\eta}=M_{d, t} \delta_{d, t} \quad \text { and } \quad M_{f, t}^{\eta}=M_{f, t}^{*} \delta_{f, t}
$$

The change of numeraire units in Eqs. (3) and (6) preserves agents' pricing of asset return uncertainty, characterized by Eq. (5), since

$$
M_{d, t} \boldsymbol{R}_{t}=\overbrace{M_{d, t} \underbrace{M_{d, t}^{\eta}}_{\boldsymbol{R}_{t}} \boldsymbol{R}_{t}^{\eta}}^{\eta}=M_{d, t}^{\eta} \boldsymbol{R}_{t}^{\eta} \quad \text { and } \quad M_{f, t}^{*} \boldsymbol{R}_{t}^{*}=\overbrace{M_{f, t}^{*} \underbrace{M_{f, t}^{\eta}}_{\boldsymbol{R}_{t}^{*}} \boldsymbol{R}_{t}^{\eta}}^{\sum_{f, t}}=M_{f, t}^{\eta} \boldsymbol{R}_{t}^{\eta} .
$$

Therefore, the log difference between agents' required compensation for exposure to asset return uncertainty is captured by

$$
\ln M_{f, t}^{\eta}-\ln M_{d, t}^{\eta}=\ln M_{f, t}^{*}-\ln M_{d, t}-\ln X_{t}
$$

Importantly, this difference does not depend on the particular choice of frictionlessly traded numeraire that is used as a common basis for comparison across agents, since any such 
numeraire yields the same real exchange rate.

According to the asset market view, when Eq. (1) holds, the change in the real exchange rate reflects the difference between the foreign and domestic agents' required compensation for exposure to asset return uncertainty. However, Eq. (1) holds when $M_{d, t}^{\eta}=M_{f, t}^{\eta}$ in Eq. (8), so these agents actually require the same, not different, compensation for exposure to the uncertainty in asset returns. Instead, the change in the real exchange rate simply reflects the difference in units - different consumption baskets of goods and services, and/or different prices for the components of those baskets - over which agents' IMRSs (and the asset returns) are expressed. This point is our main critique of the asset market view of exchange rates.

Thus, to draw conclusions from Eq. (1) about meaningful economic distinctions between agents, we must make further assumptions about the underlying economic environment beyond the asset market structure. In particular, as we show in Section 4, exchange rate data, together with Eq. (1), can be used to draw important distinctions between domestic and foreign agents if we further assume that they have the same consumption aggregators over individual goods and there are goods market frictions. However, regardless of any additional assumptions about goods markets, it still remains that the foreign and domestic agents' require the same compensation for exposure to asset return uncertainty whenever Eq. (1) holds.

\subsection{Stochastic Discount Factors (SDFs)}

Eq. (1) also characterizes a change of units for a stochastic discount factor (SDF). An SDF for $\boldsymbol{R}_{t}$ is defined as an almost surely strictly positive random variable, $M_{t}>0$, such that

$$
\mathbf{1}=\mathbb{E}\left[M_{t} \boldsymbol{R}_{t}\right]
$$

From Eq. (5), $M_{d, t}$ and $M_{f, t}^{*}$ are examples of SDFs for $\boldsymbol{R}_{t}$ and $\boldsymbol{R}_{t}^{*}$, respectively. From Eq. (7), $M_{d, t}^{\eta}=M_{d, t} \delta_{d, t}$ and $M_{f, t}^{\eta}=M_{f, t}^{*} \delta_{f, t}$ are both examples of SDFs for $\boldsymbol{R}_{t}^{\eta}$.

Eq. (1) holds if and only if $M_{d, t}^{\eta}=M_{f, t}^{\eta}$, in which case $M_{d, t}$ and $M_{f, t}^{*}$ are the same SDF, simply denominated in different units. That is, dropping the subscripts on agents' IMRSs, $M_{t}$ is an SDF for $\boldsymbol{R}_{t}=X_{t} \boldsymbol{R}_{t}^{*}$ if and only $M_{t}^{*}=M_{t} X_{t}$ is an SDF for $\boldsymbol{R}_{t}^{*}$, and vice versa.

\subsection{Illustrative Example: Complete Asset Markets}

Before closing out this section, we demonstrate how our critique applies to the special case of complete asset markets, which is the canonical example upon which the asset market view 
of exchange rates is based.

A set of asset returns is a complete market for an agent if: (i) there are no events over which the agent's IMRS varies, but the asset returns do not; and (ii) there is a unique SDF within the space of SDFs that can be expressed as a function of those asset returns (or, more precisely, there is a unique SDF within the space of SDFs that are measurable with respect to the $\sigma$-algebra generated by those asset returns). Thus, if the asset returns are a complete market for both the foreign and domestic agents, then their IMRSs are equal (when expressed over a common numeraire that is frictionlessly traded) and Eq. (1) holds.

If the asset market is complete then we can explicitly characterize the agents' IMRSs. Long (1990) shows that an SDF for $\boldsymbol{R}_{t}^{\eta}$ is given by

$$
M_{t}^{\eta}=\left(\boldsymbol{R}_{t}^{\eta} \cdot \boldsymbol{\theta}^{\star}\right)^{-1}, \quad \text { where } \quad \boldsymbol{\theta}^{\star}=\arg \max _{\boldsymbol{\theta} \cdot \mathbf{1}=1} \mathbb{E}\left[\ln \left(\boldsymbol{R}_{t}^{\eta} \cdot \boldsymbol{\theta}\right)\right] \Rightarrow \mathbb{E}\left[\left(\boldsymbol{R}_{t}^{\eta} \cdot \boldsymbol{\theta}^{\star}\right)^{-1} \boldsymbol{R}_{t}^{\eta}\right]=\mathbf{1}
$$

Karatzas and Kardaras (2007) prove that this SDF always exists (whenever there is an SDF that satisfies Eq.9). Therefore, if the asset market is complete for the foreign and domestic agents, then $M_{t}^{\eta}$ in Eq. (10) is the unique SDF for $\boldsymbol{R}_{t}^{\eta}$, and their log IMRSs must equal

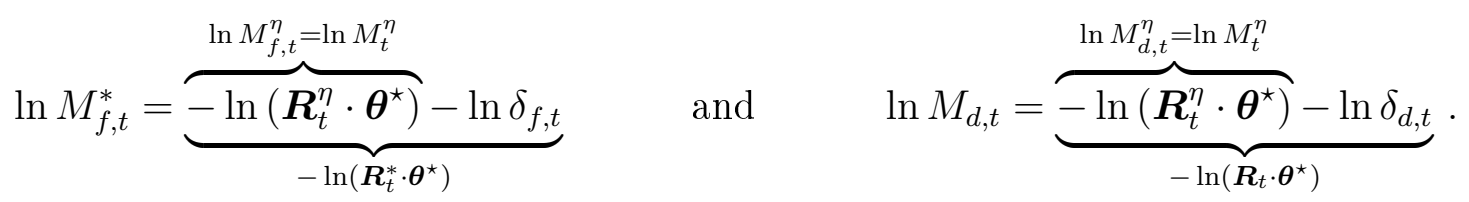

Recall that, according to the asset market view of exchange rates, the difference between agents' log IMRSs is economically interpreted as the difference between their required compensation for exposure to asset return uncertainty. However, this required compensation is captured by $\ln M_{t}^{\eta}=-\ln \left(\boldsymbol{R}_{t}^{\eta} \cdot \boldsymbol{\theta}^{\star}\right)$, which is common to both agents' log IMRSs. Instead, any difference between their IMRSs, $\ln \delta_{d, t}-\ln \delta_{f, t}=\ln X_{t}$, simply reflects the different units over which their IMRSs (and the asset returns) are expressed.

\section{Economic Interpretation of SDFs in Affine Models}

In this section we demonstrate how our critique applies to the large literature that uses reduced-form affine models of two (or more) log SDFs to characterize and economically interpret currency returns as differences between agents' IMRSs. ${ }^{3}$

\footnotetext{
${ }^{3} \mathrm{~A}$ few examples of papers that pursue this modeling approach include: Backus, Foresi, and Telmer (2001); Brandt and Santa-Clara (2002); Bakshi, Carr, and Wu (2008); Lustig, Roussanov, and Verdelhan (2011); and Lustig, Roussanov, and Verdelhan (2014).
} 
To begin, we extend our earlier notation to a setting with $\ell \geq 2$ different economies. Let $X_{t}^{i}$ denote the gross change in the $i$ th real exchange rate (expressed in units of the domestic consumption basket per unit of the consumption basket in the $i$ th foreign economy). Let $M_{t}$ and $M_{t}^{i}$ be SDFs that price the asset returns denominated in units of the domestic and $i$ th foreign consumption baskets, respectively. Let $r_{t}$ and $r_{t}^{i}$ denote the one-period continuouslycompounded real interest rates on default-free bank accounts in the domestic and $i$ th foreign economy, respectively. Finally, let $\boldsymbol{X}_{t}, \boldsymbol{M}_{t}^{*}$, and $\boldsymbol{r}_{t}^{*}$ denote $(\ell-1) \times 1$ vectors with $i$ th elements $X_{t}^{i}, M_{t}^{i}$, and $r_{t}^{i}$ respectively.

In this literature, the dynamics of SDFs for asset returns denominated in units of the $\ell$ different economies are frequently modeled as

$$
\ln M_{t}=-r_{t-1}-\boldsymbol{\lambda} \varepsilon_{t}-\frac{1}{2} \boldsymbol{\lambda} \boldsymbol{\lambda}^{\top} \quad \text { and } \quad \ln \boldsymbol{M}_{t}^{*}=-\boldsymbol{r}_{t-1}^{*}-\Lambda^{*} \varepsilon_{t}-\frac{1}{2} \operatorname{diag}\left(\Lambda^{*} \Lambda^{* \top}\right)
$$

where superscript ${ }^{\top}$ denotes the transpose of a matrix or vector, and $\operatorname{diag}(\cdot)$ denotes the main diagonal vector a matrix. In Eq. (12), $\varepsilon_{t} \sim \mathcal{N}(\mathbf{0}, \mathcal{I})$ is a $k \times 1$ vector of independent standard normals, $\boldsymbol{\lambda}$ is a $1 \times k$ vector, and $\Lambda^{*}$ is an $(\ell-1) \times k$ matrix. For notational convenience, we suppress any time/state dependence of the parameters (i.e., $\boldsymbol{\lambda} \equiv \boldsymbol{\lambda}_{\boldsymbol{t}}$ and $\left.\Lambda^{*} \equiv \Lambda_{t}^{*}\right)$. If the change of units, $\ln \boldsymbol{X}_{t}=\ln \boldsymbol{M}_{t}^{*}-1 \ln M_{t}$, holds for $M_{t}$ and $\boldsymbol{M}_{t}^{*}$ in Eq. (12) then the log returns on default-free bank accounts in the foreign economies, denominated in domestic consumption units, are given by

$$
\boldsymbol{r}_{t-1}^{*}+\ln \boldsymbol{X}_{t}=\mathbf{1} r_{t-1}+\underbrace{\Sigma \boldsymbol{\lambda}^{\top}-\frac{1}{2} \operatorname{diag}\left(\Sigma \Sigma^{\top}\right)}_{\frac{1}{2}\left[\mathbf{1} \boldsymbol{\lambda} \boldsymbol{\lambda}^{\top}-\operatorname{diag}\left(\Lambda^{*} \Lambda^{* \top}\right)\right]}+\Sigma \boldsymbol{\varepsilon}_{t}, \quad \text { where } \quad \Sigma=\mathbf{1} \boldsymbol{\lambda}-\Lambda^{*}
$$

In the literature we critique, the reduced-form SDFs in Eq. (12) are often assumed to equal the IMRSs of representative agents in the domestic and foreign economies. $\boldsymbol{\lambda}$ is economically interpreted as the compensation that agents in the domestic economy require for exposure to the vector of asset return shocks, $\varepsilon_{t}$. Likewise, the $i$ th row of $\Lambda^{*}$ is interpreted as the prices of risk that agents in the $i$ th foreign economy assign to these shocks. According to this economic interpretation of Eqs. (12) and (13), both the volatility and expected excess return on foreign currency investments reflect heterogeneity across agents in different economies in the compensation they require for exposure to these asset market shocks. 


\subsection{Example: Lustig, Roussanov, and Verdelhan (2014)}

Lustig, Roussanov, and Verdelhan (2014) is a recent and representative example in the literature that we critique. They document that currency returns can be explained by a small set of currency factors (i.e., dynamic long/short portfolios of currencies). To interpret these empirical results, they provide a reduced-form affine model of agents' IMRSs that is driven by a vector of $\ell+2$ latent shocks, $\varepsilon_{t}$. Their model is of the form in Eqs. (12) and (13), with

$$
\Lambda^{*}=\left[\begin{array}{ccccccc}
\lambda_{1}^{1} & 0 & \cdots & 0 & 0 & \lambda_{\ell+1}^{1} & \lambda_{\ell+2}^{1} \\
0 & \lambda_{2}^{2} & \ddots & \vdots & \vdots & \lambda_{\ell+1}^{2} & \lambda_{\ell+2}^{2} \\
\vdots & \ddots & \ddots & 0 & \vdots & \vdots & \vdots \\
0 & \cdots & 0 & \lambda_{\ell-1}^{\ell-1} & 0 & \lambda_{\ell+1}^{\ell-1} & \lambda_{\ell+2}^{\ell-1}
\end{array}\right]
$$

and

$$
\boldsymbol{\lambda}=\left[\begin{array}{lllllll}
0 & \cdots & \cdots & 0 & \lambda_{\ell} & \lambda_{\ell+1} & \lambda_{\ell+2}
\end{array}\right] .
$$

Lustig, Roussanov, and Verdelhan (2014) interpret the last two latent shocks in their model, $\varepsilon_{t}^{\ell+1}$ and $\varepsilon_{t}^{\ell+2}$, as global shocks because agents in all economies require (possibly different) compensation for exposure to these risks. By contrast, the first $\ell$ latent shocks $\varepsilon_{t}^{1}, \ldots, \varepsilon_{t}^{\ell}$ - are viewed as country-specific because only agents in a single economy require compensation for bearing each of these risks. They argue that various properties of currency (portfolio) returns reflect heterogeneity across agents in different economies in their required compensation for exposure to these local and global asset market shocks. ${ }^{4}$

\subsection{Critique Applied to Affine Models}

To see how our critique applies to this literature, let $\boldsymbol{R}_{t}^{\eta}$ denote the vector of gross returns, denominated in units of our numeraire, on a set of $k$ non-redundant assets that are priced by the SDFs in Eq. (12). Then $\boldsymbol{R}_{t}^{i}=\delta_{f, t} \boldsymbol{R}_{t}^{\eta}$ are these asset returns, denominated in the consumption units of the $i$ th foreign economy, where $\delta_{i, t}=P_{i, t} / P_{i, t-1}$, and $P_{i, t}$ is the number of numeraire units that can be traded for one unit of the representative agent's consumption

\footnotetext{
${ }^{4}$ For example, Lustig, Roussanov, and Verdelhan (2014, p. 537) state that "Accounting for the variation in expected currency excess returns across different currencies requires variation in the SDFs' exposures to the common innovation. ... Lustig, Roussanov, and Verdelhan (2011) show that permanent heterogeneity in loadings ... is necessary to explain the variation in unconditional expected returns (why high interest rate currencies tend not to depreciate on average), whereas the transitory heterogeneity in loadings ... is necessary to match the variation in conditional expected returns (why currencies with currently high interest rates tend to appreciate)."
} 
basket at time $t$ in the $i$ th foreign economy. Likewise, $\boldsymbol{R}_{t}=\delta_{d, t} \boldsymbol{R}_{t}^{\eta}=X_{t}^{i} \boldsymbol{R}_{t}^{i}$ are these asset returns, denominated in domestic consumption units.

For tractability, given the affine log SDFs in Eq. (12), the vector of log returns on these assets are typically assumed to also be affine functions of the latent shocks, $\varepsilon_{t}$. If these $\log$ asset returns span this vector of shocks, then we can invert this relationship and express the shocks as affine functions of the log asset returns. Substituting this inversion back into Eq. (12), the log SDFs can be expressed as affine functions of the log returns,

$$
\ln M_{t}=c-\Upsilon \cdot \ln \boldsymbol{R}_{t} \quad \text { and } \quad \ln M_{t}^{i}=c_{i}-\Upsilon_{i} \cdot \ln \boldsymbol{R}_{t}^{i}, \quad \forall i \in\{1, \ldots, \ell-1\}
$$

for some $c, c_{i}, \Upsilon$, and $\Upsilon_{i}$. The change of units, $\ln X_{t}^{i}=\ln M_{t}^{i}-\ln M_{t}$, for each pair of SDFs in Eq. (15) implies that

$$
\ln M_{t}^{i}=\ln M_{t}+\ln X_{t}^{i}=c-\Upsilon \cdot \underbrace{\left(\ln \boldsymbol{R}_{t}-\mathbf{1} \ln X_{t}^{i}\right)}_{\ln \boldsymbol{R}_{t}^{i}}+(1-\boldsymbol{\Upsilon} \cdot \mathbf{1}) \ln X_{t}^{i}
$$

Comparing the expressions for $\ln M_{t}^{i}$ in Eqs. (15) and (16) give us

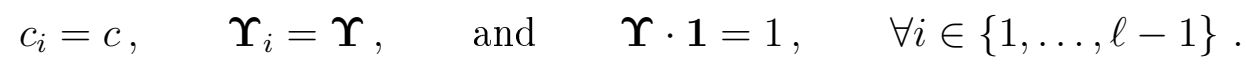

Therefore, the SDFs in Eq. (12) can be written equivalently as

$$
\ln M_{t}=\overbrace{c \underbrace{-\boldsymbol{\Upsilon} \cdot \ln \boldsymbol{R}_{t}^{\eta}}_{-\boldsymbol{\Upsilon} \cdot \ln \boldsymbol{R}_{t}}-\ln \delta_{d, t}}^{\ln M_{t}^{\eta}} \quad \text { and } \quad \ln M_{t}^{i}=\overbrace{c \underbrace{-\Upsilon \boldsymbol{\Upsilon} \cdot \ln \boldsymbol{R}_{t}^{\eta}}_{-\boldsymbol{\Upsilon} \cdot \ln \boldsymbol{R}_{t}^{i}}-\ln \delta_{i, t}^{\eta}} .
$$

Again, contrary to the claims in this literature, the relative asset returns (including currency returns) are only reflected in the common component of these SDFs, which is $\ln M_{t}^{\eta}=$ $c-\Upsilon \cdot \ln \boldsymbol{R}_{t}^{\eta}$. The difference, $\ln \delta_{d, t}-\ln \delta_{i, t}=\ln X_{t}^{i}$, instead reflects the different units used to denominate the asset returns.

To further explore affine models, note that $c$ can be characterized in terms of $\Upsilon$, since

$$
\mathbf{1}=\mathbb{E}[\underbrace{e^{c-\boldsymbol{\Upsilon} \cdot \ln \boldsymbol{R}_{t}^{\eta}}}_{M_{t}^{\eta}} \boldsymbol{R}_{t}^{\eta}] \quad \Rightarrow \quad c=-\ln \frac{1}{k} \mathbf{1} \cdot \mathbb{E}\left[e^{-\boldsymbol{\Upsilon} \cdot \ln \boldsymbol{R}_{t}^{\eta}} \boldsymbol{R}_{t}^{\eta}\right]
$$

Moreover, this characterization of $c$ can be symmetrically expressed using the asset returns 
denominated in the domestic and foreign consumption baskets, since

$$
\boldsymbol{\Upsilon} \cdot \mathbf{1}=1 \quad \Rightarrow \quad e^{-\boldsymbol{\Upsilon} \cdot \ln \boldsymbol{R}_{t}} \boldsymbol{R}_{t}=e^{-\boldsymbol{\Upsilon} \cdot \ln \boldsymbol{R}_{t}^{\eta}} \boldsymbol{R}_{t}^{\eta}=e^{-\boldsymbol{\Upsilon} \cdot \ln \boldsymbol{R}_{t}^{i}} \boldsymbol{R}_{t}^{i}, \quad \forall i
$$

In many cases we can explicitly solve for $c$ and $\Upsilon$ in Eq. (18). To illustrate, suppose the last asset is a default-free bank account, denominated in domestic consumption units, that pays continuously-compounded interest $r_{t-1}$. If the gross returns on the other $k-1$ assets, denominated in domestic consumption units, are logormally distributed with mean $\boldsymbol{\mu}$ and variance $\Omega$, then

$$
c=\frac{1}{2} \gamma \Omega \gamma^{\top}-\frac{1}{2} \gamma \cdot \operatorname{diag}(\Omega) \quad \text { and } \quad \boldsymbol{\Upsilon}=[\boldsymbol{\gamma}, 1-\boldsymbol{\gamma} \cdot \mathbf{1}]
$$

where

$$
\boldsymbol{\gamma}=\left[\boldsymbol{\mu}-\mathbf{1} r_{t-1}+\frac{1}{2} \operatorname{diag}(\Omega)\right]^{\top} \Omega^{-1}
$$

As a concrete example, if $\Sigma=\mathbf{1} \boldsymbol{\lambda}-\Lambda^{*}$ in Eq. (13) is non-singular, and $k=\ell-1$, then the log returns on the domestic and foreign bank accounts completely span the vector of shocks, $\varepsilon_{t}$. In this case,

$$
\ln \boldsymbol{R}_{t}=\left[\begin{array}{c}
\boldsymbol{r}_{t-1}^{*}+\ln \boldsymbol{X}_{t} \\
r_{t-1}
\end{array}\right], \quad \boldsymbol{\mu}=\mathbf{1} r_{t-1}+\Sigma \boldsymbol{\lambda}^{\top}-\frac{1}{2} \operatorname{diag}\left(\Sigma \Sigma^{\top}\right), \quad \text { and } \quad \Omega=\Sigma \Sigma^{\top}
$$

Therefore,

$$
\boldsymbol{\gamma}=\boldsymbol{\lambda} \Sigma^{-1} \quad \text { and } \quad c=\frac{1}{2} \boldsymbol{\lambda}\left[\boldsymbol{\lambda}^{\top}-\Sigma^{-1} \cdot \operatorname{diag}\left(\Sigma \Sigma^{\top}\right)\right], \text { where } \Sigma=\mathbf{1} \boldsymbol{\lambda}-\Lambda^{*}
$$

\subsection{Implications of No-Arbitrage}

The dynamics of short-term interest rates can also be included in models of the form in Eq. (12), in which case the model will have no-arbitrage implications for the term structure of interest rates in the domestic and foreign economies. However, Eq. (12) does not impose any such overidentifying restrictions.

A particularly well-known paper in this literature is Backus, Foresi, and Telmer (2001) who "characterize the (forward premium) anomaly in the context of affine models of the term structure of interest rates." 5 The restrictions they derive are not actually due to

\footnotetext{
${ }^{5}$ In contrast to much of the literature, Backus, Foresi, and Telmer (2001) are careful not to interpret the SDFs in their model as the IMRSs of domestic and foreign representative agents.
} 
Eqs. (12) and (13), but instead reflect an implicit spanning assumption. The intuition can be understood as follows. Any dynamic no-arbitrage model of the term structure of interest rates in two economies must have at least four assets: short- and long-term bonds in both economies. With four assets, there are three relative returns to consider. However, Backus, Foresi, and Telmer (2001) assume that those three relative returns are driven by only two shocks, in which case one (or a portfolio) of the three assets must be redundant, since it can be replicated by a combination of the other two. It is this redundancy, not the forward premium anomaly or Eqs. (12) and (13), that is the source of the restrictions they derive.

It is also important to recognize that Eq. (1) does not imply that a foreign currency return is a redundant asset that can be replicated by a combination of other assets. For example, Ahn (2004) provides a model in which shocks to real exchange rates are not completely spanned by the shocks that drive bond returns denominated in local units. The model in Lustig, Roussanov, and Verdelhan (2014) also has this feature. ${ }^{6}$

\section{Restrictions in Reduced-Form Models}

Beyond the economic interpretation of SDFs, some papers in the literature we critique suggest that the change of units in Eq. (1) also imposes restrictions on reduced-form models of currency returns. It does not. In this section we show that the restrictions in these papers are actually errors.

\subsection{SDFs for Different Sets of Assets}

Brennan and Xia (2006) test whether the change of units, $\ln \boldsymbol{X}_{t}=\ln \boldsymbol{M}_{t}^{*}-\mathbf{1} \ln M_{t}$, holds for SDFs, $M_{t}$ and $\boldsymbol{M}_{t}^{*}$, that they estimate to only price domestic and foreign bonds, respectively. However, this test is not motivated by theory, since the change of units only applies to SDFs that price the same set of assets. To demonstrate this point with a simple counterexample, note that $\ln M_{t}=-r_{t-1}$ and $\ln \boldsymbol{M}_{t}^{*}=-\boldsymbol{r}_{t-1}^{*}$ are $\log$ SDFs that only price domestic and foreign one-period default-free bank account returns denominated in local units. However, if the exchange rate is not determined prior to time $t$ (i.e., it is stochastic), then

\footnotetext{
${ }^{6}$ In Lustig, Roussanov, and Verdelhan (2014), a single shock, $\varepsilon_{t}^{\ell+2}$, drives all of the variation in the $\ell-1$ exchange rates that is independent of changes in the term structure of interest rates in those economies. In their model, the short-term interest rate in the $i$ th foreign economy, $r_{t}^{i}$, is driven by $\varepsilon_{t}^{i}$ and $\varepsilon_{t}^{\ell+1}$, while the interest rate in the domestic economy, $r_{t}$, is driven by $\varepsilon_{t}^{\ell}$ and $\varepsilon_{t}^{\ell+1}$. The shocks $\varepsilon_{t}^{i}$ and $\varepsilon_{t}^{\ell}$ also drive timevariation in $\lambda_{i}^{i}$ and $\lambda_{\ell}$, while $\varepsilon_{t}^{\ell+1}$ also drives variation in $\lambda_{\ell+1}, \lambda_{\ell+2}, \lambda_{\ell+1}^{i}$, and $\lambda_{\ell+2}^{i}$. Given this dependence, the term structure of interest rates in each economy is determined by no-arbitrage, and is driven by the same two shocks that drive short-term interest rates in that economy.
} 


$$
\ln \boldsymbol{X}_{t} \neq \ln \boldsymbol{M}_{t}^{*}-\mathbf{1} \ln M_{t}=\mathbf{1} r_{t-1}-\boldsymbol{r}_{t-1}^{*}
$$

\subsection{Minimum Variance Projections}

Let $\boldsymbol{\beta} \cdot \boldsymbol{R}_{t}$ be the linear projection of the domestic representative agent's IMRS onto the asset returns denominated in domestic consumption units. Likewise, let $\boldsymbol{\beta}^{*} \cdot \boldsymbol{R}_{t}^{*}$ be the linear projection of the foreign representative agent's IMRS onto the asset returns in foreign consumption units. Brandt, Cochrane, and Santa-Clara (2006, p. 675) claim that $\boldsymbol{\beta} \cdot \boldsymbol{R}_{t} X_{t}$ is always in the linear span of $\boldsymbol{R}_{t}^{*}$, which implies that Eq. (1) generalizes to incomplete markets if we replace agents' IMRSs with these minimum variance projections. ${ }^{7}$ In general, this claim is not correct. Instead, it is $\boldsymbol{\beta} \cdot \boldsymbol{R}_{t} / X_{t}$, not $\boldsymbol{\beta} \cdot \boldsymbol{R}_{t} X_{t}$, that is always in the linear span of $\boldsymbol{R}_{t}^{*}=\boldsymbol{R}_{t} / X_{t}{ }^{8}$ If the asset market is incomplete then, for any given $\boldsymbol{\beta}$ there does not generally exist $\boldsymbol{\beta}^{*}$ such that $\boldsymbol{\beta}^{*} \cdot \boldsymbol{R}_{t}^{*}=\boldsymbol{\beta} \cdot \boldsymbol{R}_{t} X_{t}$, and therefore,

$$
\ln X_{t} \neq \ln \boldsymbol{\beta}^{*} \cdot \boldsymbol{R}_{t}^{*}-\ln \boldsymbol{\beta} \cdot \boldsymbol{R}_{t}
$$

\subsection{Incomplete Markets}

Brandt and Santa-Clara (2002) provide a reduced-form model of different SDFs, $M_{t}$ and $M_{t}^{*}$, such that

$$
\ln \Xi_{t}=\ln M_{t}^{*}-\ln M_{t}-\ln X_{t} \neq 0
$$

However, they claim that $\Xi_{t}$ is independent of $M_{t}$ and $M_{t}^{*}$, with $\mathbb{E}\left[\Xi_{t}^{-1}\right]=1 .^{9}$

This claim violates no arbitrage because it implies that their model assigns two different returns to the same default-free domestic currency bank account. To prove this result, note that $M_{t}^{*} \boldsymbol{R}_{t}^{*}=M_{t} \Xi_{t} \boldsymbol{R}_{t}$. Therefore $M_{t}$ and $M_{t} \Xi_{t}$ must both price the asset returns, $\boldsymbol{R}_{t}$, including a default-free domestic currency bank account,

$$
\mathbb{E}\left[M_{t}\right]=e^{-r_{t-1}}=\mathbb{E}\left[M_{t} \Xi_{t}\right]
$$

\footnotetext{
${ }^{7}$ Lustig and Verdelhan (2012, p. 395) also make this claim in their survey chapter.

${ }^{8}$ In the appendix of their paper, Brandt, Cochrane, and Santa-Clara (2006) provide a specific example with complete asset markets in which $\boldsymbol{\beta} \cdot \boldsymbol{R}_{t} X_{t}$ is in the linear span of $\boldsymbol{R}_{t}^{*}$. However, this result does not hold true in general if markets are incomplete (which is the relevant case required to prove their desired result).

${ }^{9}$ See Eq. (24) in Brandt and Santa-Clara (2002, p. 176). They state that "the key insight of our model is that when markets are incomplete, the volatility of the exchange rate is not uniquely determined by the domestic and foreign stochastic discount factors. ... If markets are incomplete, the volatility of the exchange rate can contain an element that is orthogonal to the priced sources of risk in both countries. ... To capture this excess volatility, we specify a stochastic process for the degree of market incompleteness."
} 
However, if $\Xi_{t}$ is independent of $M_{t}$ and $M_{t}^{*}$, then by Jensen's inequality,

$$
\mathbb{E}\left[M_{t} \Xi_{t}\right]>\mathbb{E}\left[M_{t}\right] / \mathbb{E}\left[\Xi_{t}^{-1}\right]=\mathbb{E}\left[M_{t}\right] \cdot{ }^{10}
$$

\subsection{Market Completeness in Reduced-Form Models}

In reduced-form models of asset returns, there is a unique SDF (or, equivalently, a unique pricing measure) if and only if any contingent claim on the assets can be exactly replicated by a (dynamic) portfolio of the assets. ${ }^{11}$ Since reduced-form models focus exclusively on asset returns, the SDFs in these models can only be unique within the space of SDFs that are measurable with respect to the $\sigma$-algebra generated by these returns. The binomial tree and Black-Scholes-Merton models are perhaps the best known examples of reduced-form models with SDFs that are unique in this sense. ${ }^{12}$

While the unique SDFs in these reduced-form models are useful for pricing and hedging contingent claims (e.g., options), they do not necessarily equal the IMRS of a representative agent in Eq. (1). For example, when there is a unique reduced-form SDF for the asset returns denominated in domestic consumption units, it can be expressed as $\ln M_{t}=-\ln \left(\boldsymbol{R}_{t} \cdot \boldsymbol{\theta}^{\star}\right)$. However, the domestic agent's IMRS could be $M_{d, t}=\zeta_{t} M_{t}$, where $\zeta_{t}$ is a random variable that is independent of $\boldsymbol{R}_{t}$ with $\mathbb{E}\left[\zeta_{t}\right]=1$. In this case, $M_{d, t}$ is an SDF for $\boldsymbol{R}_{t}$, but the agent's IMRS varies over states of the world, captured by $\zeta_{t}$, that the asset returns do not (i.e., $M_{d, t}$ is not measurable with respect to the $\sigma$-algebra generated by $\boldsymbol{R}_{t}$ ).

Thus, an SDF in a reduced-form model can only be economically interpreted as the IMRS of a representative agent under the additional assumption that there are no events (i.e., states of the world) over which the agent's IMRS varies, but the asset returns in the model do not. This additional assumption is common in more structural models (with agents) because it makes them much easier to solve. However, it is not a common assumption in reduced-form

\footnotetext{
${ }^{10}$ Similarly, Anderson, Hammond, and Ramezani (2010) show that, in the special case of an affine setting, the assumptions in Brandt and Santa-Clara (2002) are infeasible. Eq.(29) illustrates that the internal inconsistency (i.e., the arbitrage opportunity) applies more generally, beyond the specific affine structure.

${ }^{11}$ See the seminal work by Harrison and Kreps (1979) and Harrison and Pliska (1981, 1983).

${ }^{12}$ For details on the binomial tree model, see Cox, Ross, and Rubinstein (1979). For the Black-ScholesMerton model, see Black and Scholes (1973) and Merton (1973). The discrete-time (continuous state space) model in Eqs. (12) and (13) is an example of a reduced-form model that does not have a unique SDF; for example, Long's SDF in Eq. (10) is another, different SDF that is also consistent with the asset return dynamics. However, the continuous-time limit of Eq.(12) is a continuous diffusion and in that case, $\Upsilon$ in Eq. (18) is equal to $\boldsymbol{\theta}^{\star}$ in Eq. (10).
} 
models (outside of the international asset pricing literature). In fact, the primary appeal of reduced-form models is that one is free to model the relative returns on a subset of the assets available to trade, and can be agnostic about any variation in agents' IMRSs that is independent of the returns on those (or any other) assets.

\section{Models with Agents and Risk Sharing}

We now turn to a discussion of models in which there are two agents, who reside, respectively, in the domestic and foreign economies. In Section 4.1 we highlight the model elements that are particularly relevant for our subsequent discussion. In Section 4.2 we characterize the conditions under which variation in the real exchange rate directly reflects imperfect risk sharing. In Section 4.3 we show that asset returns can be informative about the amount of risk shared between agents, but not about the amount of unshared risk. Finally, in Section 4.4, we work with a simple model motivated by Backus and Smith (1993), to show that fundamentally different models of real exchange rates can be observationally equivalent at the level of aggregate consumption data.

\subsection{Model Highlights}

We describe an economy with two countries (domestic and foreign), each with a representative agent. Utility is defined over $n$ individual consumption goods, which are indexed by $j=1,2, \ldots, n$. All goods are perishable and both agents are price takers. Time is discrete, and indexed by $t$, but we suppress date subscripts unless strictly necessary.

The domestic agent has an instantaneous level of utility

$$
u\left[c_{d}\left(c_{d}^{1}, c_{d}^{2}, \cdots, c_{d}^{n}\right)\right]
$$

where $c_{d}^{j}$ is her consumption of $\operatorname{good} j, c_{d}(\cdot)$ is a homogeneous of degree one quasi-concave function of its arguments, and $u$ is a monotonic function with standard properties. The foreign agent has an instantaneous level of utility

$$
u\left[c_{f}\left(c_{f}^{1}, c_{f}^{2}, \cdots, c_{f}^{n}\right)\right]
$$

where $c_{f}^{j}$ is his consumption of $\operatorname{good} j$, and $c_{f}(\cdot)$ is a homogeneous of degree one quasiconcave function of its arguments. For convenience we assume that the utility functions 
over the aggregate are the same, but that the consumption aggregators, $c_{d}$ and $c_{f}$ may be different.

Both economies are cashless and use good 1 as the numeraire, which is assumed to be frictionlessly traded. Our model would have the same implications for the real exchange rate if we chose different numeraires. Goods markets meet sequentially. Goods may or may not be frictionlessly traded, so prices for those goods may differ across the economies. Price differences might be the result of physical trading costs (in the extreme, some goods might be nontraded) or might stem from price discrimination by producers. The domestic and foreign prices of good $j$ are, respectively, $P_{d}^{j}$ and $P_{f}^{j}$. For any good that is frictionlessly traded, its price must be the same in both countries:

$$
P_{d}^{j}=P_{f}^{j}
$$

Given that good 1 is the numeraire, $P_{d}^{1}=P_{f}^{1}=1$.

Let $M_{d, t}^{j}$ denote the domestic agent's IMRS, and $M_{f, t}^{j}$ denote the foreign agent's IMRS, defined over units of an individual good, $j$, between periods $t-1$ and $t$. Later, we assume that lifetime utility is additively time separable, with a discount factor, $0<\beta<1$, so that $M_{d, t}^{j}=\beta\left[\partial u_{c}\left(c_{d, t}\right) / \partial c_{d, t}^{j}\right] /\left[\partial u_{c}\left(c_{d, t-1}\right) / \partial c_{d, t-1}^{j}\right]$. However, for most of this section, lifetime utility can take on a number of different forms with the same results going through.

We assume that both agents have access to a financial market in which $k$ assets, priced in units of the numeraire, are frictionlessly traded. In any model where the asset market is complete $M_{d, t}^{1}=M_{f, t}^{1}$. This follows from the fact that an economy in which the asset market is complete is equivalent to one in which there is a complete set of state-contingent claims. In such an economy, both agents optimally set, on a state-by-state basis, the IMRS between units of the numeraire at $t$ and $t-1$ equal to the price, at $t-1$, of a claim to a unit of the numeraire in each possible state at time $t$. This result is standard and does not depend on details of the utility function or the rest of the economic environment, such as the production structure. In a more general model where the asset market is incomplete, there will be some time periods or states of the world in which $M_{d, t}^{1} \neq M_{f, t}^{1}$. We find it useful to define $\Xi_{t}=M_{f, t}^{1} / M_{d, t}^{1}$, with deviations of $\Xi_{t}$ from 1 reflecting the degree of asset market incompleteness.

In a model where households are price takers, the marginal rate of substitution between good $j$ and good 1 is optimally set equal to the price of good $j$, given that good 1 is the numeraire. Consequently, for the domestic and foreign agents, respectively, $M_{d, t}^{j} / M_{d, t}^{1}=$ $P_{d, t}^{j} / P_{d, t-1}^{j}$ and $M_{f, t}^{j} / M_{f, t}^{1}=P_{f, t}^{j} / P_{f, t-1}^{j}$. 
Thus, in general, the following equilibrium condition holds:

$$
\frac{M_{f, t}^{j}}{M_{d, t}^{j}}=\Xi_{t} \frac{\left(P_{f, t}^{j} / P_{f, t-1}^{j}\right)}{\left(P_{d, t}^{j} / P_{d, t-1}^{j}\right)}
$$

If trade in good $j$ is frictionless-or in other words, if purchasing power parity (PPP) holds for good $j$, then $P_{d, t}^{j}=P_{f, t}^{j}$ for all $t$, and the price change terms drop out of the equation.

Definition. The domestic and foreign agents share risk perfectly if $M_{f, t}^{j}=M_{d, t}^{j}$ for all $j, t$.

Colacito and Croce (2011, p. 156) also adopt this definition of perfect risk sharing, which states that the domestic and foreign agents equate IMRSs over all individual goods and services at every point in time. It is not equivalent to asset markets being complete, which would only imply that $\Xi_{t}=1$ for all $t$. Nor is it equivalent to an allocation that coincides with the solution to a social planner's problem that respects goods market frictions. In either of these situations, risk sharing will be as good as it can be, but any market frictions that result in a wedge between $P_{d, t}^{j}$ and $P_{f, t}^{j}$, for some $j$, prevent IMRSs over some goods being equated. Our definition means that risk sharing is perfect in a model with complete asset markets and frictionless trade in all goods.

IMRSs may also be defined over consumption baskets rather than individual consumption goods. We let $M_{d, t}$ denote the domestic agent's IMRS defined over units of her consumption basket, and $M_{f, t}^{*}$ denote the foreign agent's IMRS, defined over units of his consumption basket. We use an asterisk to denote the foreign agent's IMRS because the foreign agent may have different preferences over individual goods than the domestic agent. This would imply that the two IMRSs are expressed in different units. Given that the agents' baskets are homogeneous of degree one aggregates of their consumption of individual goods, the prices of these baskets (in some common numeraire) may be written as homogenous of degree one functions of the individual prices (in the same numeraire) faced by these agents: $P_{d}=H_{d}\left(P_{d}^{1}, P_{d}^{2}, \cdots\right)$ and $P_{f}=H_{f}\left(P_{f}^{1}, P_{f}^{2}, \cdots\right)$, with the functional forms of $H_{d}(\cdot)$ and $H_{f}(\cdot)$ being related to the functions $c_{d}(\cdot)$ and $c_{f}(\cdot)$ (see Varian, 1984). The subscripts on these functions allow for the possibility that the agents' preferences differ. At the level of aggregate consumption the equation that corresponds to Eq. (33) is

$$
\frac{M_{f, t}^{*}}{M_{d, t}}=\Xi_{t} X_{t},
$$

where $X_{t}=e_{t} / e_{t-1}$ and $e_{t}=P_{f, t} / P_{d, t}$. 


\subsection{Risk Sharing and Variation in Real Exchange Rates}

When agents have the same consumption aggregator, $H_{d}=H_{f}=H$, the real exchange rate is $e_{t}=H\left(P_{f, t}^{1}, P_{f, t}^{2}, \cdots\right) / H\left(P_{d, t}^{1}, P_{d, t}^{2}, \cdots\right)$. If goods markets are frictionless then $P_{d, t}^{j}=P_{f, t}^{j}$ for all $j, t$. Therefore, if agents have the same consumption aggregator and goods markets are frictionless, $e_{t}=1$ and $X_{t}=1$ for all $t$. If we observe real exchange rate variation, it necessarily implies that either markets for some goods are not frictionless or agents have different consumption aggregators (or both).

Does a variable real exchange rate, by itself, directly reflect imperfect risk sharing? Brandt, Cochrane, and Santa-Clara (2006) argue very strongly that the answer is always yes. Table 1 summarizes our answer to this question, and as the table indicates, it depends on underlying assumptions about the economic environment. The answer is "yes" if we assume that asset markets are complete, and that agents have identical consumption aggregators. With these assumptions, $\Xi_{t}=1$ and variation in $X_{t}$ (due to variation in the real exchange rate, $\left.e_{t}\right)$ can only happen if there are goods market frictions that drive wedges between $P_{d, t}^{j} / P_{d, t-1}^{j}$ and $P_{f, t}^{j} / P_{f, t-1}^{j}$ for some $j$. The existence of such wedges, in turn, necessarily implies imperfect risk sharing.

Under any of the other combinations of assumptions shown in Table 1, however, the answer is "no". For example, in the "northeast" corner of the table, asset markets are assumed to be complete, but preferences over goods differ $\left(H_{d} \neq H_{f}\right)$. In this case, perfect risk sharing and real exchange rate variation are compatible, because we can have $M_{d, t}^{j}=M_{f, t}^{j}$ for all $j$, $t$, even when $M_{d, t} \neq M_{f, t}^{*}$.

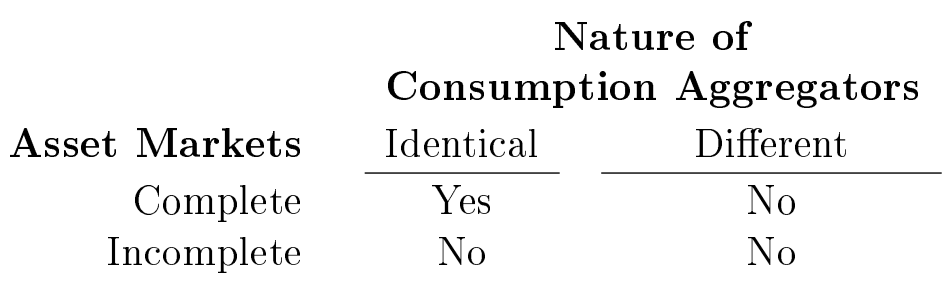

Table 1: Does a variable real exchange rate directly reflect imperfect risk sharing?

In the bottom row of the table the answer is also "no". When asset markets are incomplete, or, more precisely, when $\Xi_{t} \neq 1$ for some $t$, then risk sharing is imperfect regardless of the behavior of the real exchange rate. For example, goods markets could be frictionless (implying that $P_{d, t}^{j}=P_{f, t}^{j}$ for all $j, t$ ) and preferences over goods could be identical (with the further implication that $e_{t}=1$, for all $t$ ) but we would nonetheless have $M_{f, t}^{j} / M_{d, t}^{j}=\Xi_{t} \neq 1$ 
for some $t$.

To summarize, there is no direct connection between risk sharing and real exchange rate variation except in models where asset markets are complete and agents have identical consumption aggregators. In that case, goods market frictions are the only source of difference between agents' IMRSs.

\subsection{Asset Prices and Unshared Risks}

In contrast to our discussion in the previous section, Brandt, Cochrane, and Santa-Clara (2006) argue very strongly that real exchange rate variation is always informative about risk sharing. In fact, they conclude that because real exchange rate variation is small compared to Hansen and Jagannathan (1991) bounds on the volatility of domestic and foreign SDFs, domestic and foreign marginal utility growths must be highly correlated, and risk sharing must be "better than you think". On page 673, Brandt, Cochrane, and Santa-Clara (2006) emphasize that their conclusion is drawn by only using data on asset returns and real exchange rates:

Yet the conclusion is hard to escape. Our calculation uses only price data, and no quantity data or economic modeling (utility functions, income or productivity shock processes, and so forth). A large degree of international risk sharing is an inescapable logical conclusion of Eq. (1), a reasonably high equity premium (over $1 \%$, as we show below), and the basic economic proposition that price ratios measure marginal rates of substitution.

To understand why Brandt, Cochrane, and Santa-Clara (2006) draw this different conclusion, consider a version of their quantitative risk sharing index, applied to the logarithms of the IMRSs in our structural model $\left(m_{f, t}^{*}=\ln M_{f, t}^{*}\right.$ and $\left.m_{d, t}=\ln M_{d, t}\right)$. The index is based on the variance of $m_{f, t}^{*}-m_{d, t}$ relative to the sum of the variances of $m_{f, t}^{*}$ and $m_{d, t}::^{13}$

$$
\mathrm{RSI}=1-\frac{\operatorname{var}\left(m_{f, t}^{*}-m_{d, t}\right)}{\operatorname{var}\left(m_{f, t}^{*}\right)+\operatorname{var}\left(m_{d, t}\right)}
$$

Given our discussion in Section 4.2, it is clear that to base a risk sharing measure on RSI, one must assume that preferences across goods are identical across locations. In other words,

\footnotetext{
${ }^{13}$ The index is the same as the correlation between $m_{f t}^{*}$ and $m_{d t}$ when they have the same variance, because RSI $=2 \operatorname{cov}\left(m_{f t}^{*}, m_{d t}\right) /\left[\operatorname{var}\left(m_{f t}^{*}\right)+\operatorname{var}\left(m_{d t}\right)\right]$.
} 
one has to rule out the second column of Table 1 to make the calculation meaningful. This unstated assumption is implicit in their calculation.

Brandt, Cochrane, and Santa-Clara (2006) appeal to Hansen-Jagannathan bounds in order to avoid structurally modeling $m_{f, t}^{*}$ and $m_{d, t}$. In particular, they note that using asset market data they can project $M_{f, t}^{*}$ and $M_{d, t}$ onto common vectors of asset returns (denominated in real foreign and domestic currency, respectively). We denote the logs of these projections as $\hat{m}_{f, t}^{*}=\ln \hat{M}_{f, t}^{*}$ and $\hat{m}_{d, t}=\ln \hat{M}_{d, t}$. If we assume that $\operatorname{var}\left(m_{f, t}^{*}\right) \geq$ $\operatorname{var}\left(\hat{m}_{f, t}^{*}\right)$ and $\operatorname{var}\left(m_{d, t}\right) \geq \operatorname{var}\left(\hat{m}_{d, t}\right)$ then we can put a lower bound on RSI: ${ }^{14}$

$$
\mathrm{RSI} \geq \underline{\mathrm{RSI}}=1-\frac{\operatorname{var}\left(m_{f, t}^{*}-m_{d, t}\right)}{\operatorname{var}\left(\hat{m}_{f t}^{*}\right)+\operatorname{var}\left(\hat{m}_{d, t}\right)}
$$

Of course, $m_{f, t}^{*}$ and $m_{d, t}$ remain in the numerator in Eq. (36). In our model $m_{f, t}^{*}-m_{d, t}=$ $\xi_{t}+x_{t}$, where $\xi_{t}=\ln \Xi_{t}$ and $x_{t}=\ln X_{t}$. We can treat $x_{t}$ as measurable without a model, given data on consumer price indices and the nominal exchange rate. But $\xi_{t}$ is not directly observable. To get around this issue Brandt, Cochrane, and Santa-Clara (2006) again appeal to the projections, $\hat{m}_{f, t}^{*}$ and $\hat{m}_{d, t}$, and argue that $\hat{m}_{f t}^{*}-\hat{m}_{d, t}=x_{t}$ always holds, even when $m_{f, t}^{*}-m_{d, t} \neq x_{t}{ }^{15}$ Therefore, they use the following risk sharing measure:

$$
\mathrm{RSI}_{\mathrm{BCS}}=1-\frac{\operatorname{var}\left(x_{t}\right)}{\operatorname{var}\left(\hat{m}_{f, t}^{*}\right)+\operatorname{var}\left(\hat{m}_{d, t}\right)} .
$$

The advantage of Brandt, Cochrane, and Santa-Clara's measure is that $\hat{m}_{f, t}^{*}, \hat{m}_{d, t}$ and $x_{t}$ can be constructed using nothing more than data on asset returns and real exchange rates, and a minimal appeal to asset pricing theory in forming the projections. The problem, however, is that, unlike $\underline{\mathrm{RSI}}, \mathrm{RSI}_{\mathrm{BCS}}$ is not a lower bound for RSI. To make $\mathrm{RSI}_{\mathrm{BCS}}$ meaningful as a lower bound for RSI we have to assume that asset markets are complete, so that $\xi_{t}=0$. In other words, we have to rule out the second column and the second row of Table 1.

One interpretation of $\mathrm{RSI}_{\mathrm{BCS}}$ is that $\operatorname{var}\left(x_{t}\right) /\left[\operatorname{var}\left(\hat{m}_{f, t}^{*}\right)+\operatorname{var}\left(\hat{m}_{d, t}\right)\right]=1-\mathrm{RSI}_{\mathrm{BCS}}$ provides an upper bound on the amount of risk that is not shared due only to goods market frictions. Of course, this calculation still requires that we assume away preference differences across the agents. It also abstracts from any covariance there might be between $x_{t}$ and $\xi_{t}$.

Clearly, however, $\mathrm{RSI}_{\mathrm{BCS}}$ is silent on the amount of risk that is not shared due to asset

\footnotetext{
${ }^{14}$ While $\operatorname{var}\left(M_{f, t}^{*}\right) \geq \operatorname{var}\left(\hat{M}_{f, t}^{*}\right)$ and $\operatorname{var}\left(M_{d, t}\right) \geq \operatorname{var}\left(\hat{M}_{d, t}\right)$, it does not necessarily follow that $\operatorname{var}\left(m_{f, t}^{*}\right) \geq$ $\operatorname{var}\left(\hat{m}_{f, t}^{*}\right)$ and $\operatorname{var}\left(m_{d, t}\right) \geq \operatorname{var}\left(\hat{m}_{d, t}\right)$. This assumption is useful for intuition, but our argument does not hinge on it.

${ }^{15}$ As we showed in Section 3.2, in general $\hat{m}_{f, t}^{*}-\hat{m}_{d, t} \neq x_{t}$.
} 
market incompleteness (the $\xi_{t}$ component). This issue brings us back to a problem we highlighted in the section on reduced form models. These models are silent about differences between agents. Consistent with our main message in Sections 1-3, asset returns, alone, can provide useful information about how much risk is shared (via Hansen-Jagannathan bounds), but any measure of the degree of risk sharing also requires a measure of the amount of unshared risk. Likewise, any measure of the correlation between agents' IMRSs also requires a measure of $\xi_{t}$. Of course, one is always free to introspect, as Brandt, Cochrane, and SantaClara (2006) do in Sec. 3.5 of their paper, on how much unshared risk seems "reasonable". Our view is that this introspection is merely speculative if additional data and theory are not brought into the picture. Additionally, this introspection is not informed by exchange rates and applies equally well to agents living in the same economy, who face the same prices.

\subsection{Observational Equivalence}

In this section, we use a more specific model to highlight the fact that fundamentally different models of real exchange rates can be observationally equivalent at the level of aggregate consumption data. The model is similar to the one in Backus and Smith (1993), in being an endowment economy, with two agents, two periods, and two goods. As above, we allow preferences across individual goods to vary across agents in the two economies. The utility function, $u$, is logarithmic in the consumption aggregate, while the consumption aggregators are $c_{d}\left(c_{d}^{1}, c_{d}^{2}\right)=\left(c_{d}^{1}\right)^{\theta_{d}}\left(c_{d}^{2}\right)^{1-\theta_{d}}$ and $c_{f}\left(c_{f}^{1}, c_{f}^{2}\right)=\left(c_{f}^{1}\right)^{\theta_{f}}\left(c_{f}^{2}\right)^{1-\theta_{f}}$. Given these assumptions, it is straightforward to solve for the dynamics of the real exchange rate for a number of different variants of the model, as shown in the Online Appendix.

When assets markets are complete, representative agents in the two economies have different preferences over two individual goods, and trade in goods is frictionless, we have

$$
\begin{aligned}
& \ln \left(c_{d, t} / c_{d, t-1}\right)=\theta_{d} \ln G_{t}^{1}+\left(1-\theta_{d}\right) \ln G_{t}^{2}, \quad \text { and } \\
& \ln \left(c_{f, t} / c_{f, t-1}\right)=\theta_{f} \ln G_{t}^{1}+\left(1-\theta_{f}\right) \ln G_{t}^{2} .
\end{aligned}
$$

Here, $G_{t}^{1}$ and $G_{t}^{2}$ are, respectively, the gross growth rates of the global endowments of goods 1 and 2. Models of this type, which emphasize the role of different preferences over individual goods, have been important workhorses in the modern exchange rate literature. ${ }^{16}$

Consider an alternative model, in which assets markets are complete, representative

\footnotetext{
${ }^{16}$ See, for example, Stockman (1980), Bekaert (1996), Stathopoulos (2017), or Colacito, Croce, Ho, and Howard (2018).
} 
agents in two economies have identical preferences over the two goods, good 1 being frictionlessly traded, but good 2 being nontraded. Then we have

$$
\begin{aligned}
& \ln \left(\tilde{c}_{d, t} / \tilde{c}_{d, t-1}\right)=\theta \ln \tilde{G}_{t}^{1}+(1-\theta) \ln \tilde{g}_{d t}^{2}, \quad \text { and } \\
& \ln \left(\tilde{c}_{f, t} / \tilde{c}_{f, t-1}\right)=\theta \ln \tilde{G}_{t}^{1}+(1-\theta) \ln \tilde{g}_{f t}^{2} .
\end{aligned}
$$

Here $\theta$ is the weight that the domestic and foreign agents have on good 1 in their utility functions, $\tilde{c}_{d, t}$ and $\tilde{c}_{f, t}$ are the aggregate consumption levels in the domestic and foreign countries, $\tilde{G}_{t}^{1}$ is the growth rate of the global endowment of good 1 , and $\tilde{g}_{d t}^{2}$ and $\tilde{g}_{f t}^{2}$ are, respectively, the growth rates of the endowments of good 2 in the domestic and foreign economies. Models that emphasize simple trade frictions have also played a prominent role in the modern exchange rate literature. ${ }^{17}$

The two models are observationally equivalent for the real exchange rate when they are observationally equivalent with respect to aggregate consumption. As an example, we can specify the stochastic processes for the endowments so that

$$
\begin{aligned}
\tilde{G}_{t}^{1} & =G_{t}^{1}, \\
\ln \tilde{g}_{d, t}^{2} & =\left[\left(\theta_{d}-\theta\right) \ln G_{t}^{1}+\left(1-\theta_{d}\right) \ln G_{t}^{2}\right] /(1-\theta), \quad \text { and } \\
\ln \tilde{g}_{f, t}^{2} & =\left[\left(\theta_{f}-\theta\right) \ln G_{t}^{1}+\left(1-\theta_{f}\right) \ln G_{t}^{2}\right] /(1-\theta) .
\end{aligned}
$$

With these assumptions, the two models have the same consumption growth rates and real exchange rate:

$$
\begin{aligned}
\ln X_{t} & =\ln \left(c_{d, t} / c_{d, t-1}\right)-\ln \left(c_{f, t} / c_{f, t-1}\right) \\
& =\left(\theta_{d}-\theta_{f}\right)\left(\ln G_{t}^{1}-\ln G_{t}^{2}\right)=(1-\theta)\left(\ln \tilde{g}_{d, t}^{2}-\ln \tilde{g}_{f, t}^{2}\right) .
\end{aligned}
$$

The implication of this example is that an econometrician would not be able to discern which mechanism is more relevant without looking at consumption and endowments at the level of individual goods. The two models are also very different in terms of risk sharing. In one model, risk is shared perfectly, and only global endowments matter. When the global endowment of good 1 rises faster than that of good 2 and the foreign agent puts more weight on good 1, its relative abundance means the real exchange rate falls. ${ }^{18}$ In the other

\footnotetext{
${ }^{17}$ See, for example, for example, Backus and Smith (1993), Tesar (1993), Stockman and Tesar (1995) or Ready, Roussanov, and Ward (2017).

${ }^{18}$ In fact, this model is equivalent to a model of a single representative agent whose preference weight is a weighted average of $\theta_{d}$ and $\theta_{f}$. The equilibrium price of good 2 is identical. The real exchange rate can be
} 
model, risk sharing is imperfect when the endowment growth rates for good 2 differ across countries. If the foreign agent's endowment of good 2 grows faster, this makes his basket relatively abundant, and the real exchange rate falls.

It should also be clear, of course, that if one were to estimate these structural models using only the pricing equations expressed in terms of consumption aggregates, it would be impossible to distinguish between model variants in which (i) asset markets are complete or incomplete, (ii) agents have the same or different preferences over individual goods, and (iii) trade in goods is frictionless or not. A direct test of the model based on Eq. (34), à la Backus and Smith (1993) would face the same problem.

This is not to say that it is impossible to distinguish between models with imperfect or perfect risk sharing. We simply have to look beyond their implications for asset pricing equations and the joint behavior of aggregate consumption and exchange rates to find their predictions for individual goods or categories of goods. While this is not possible in cases where only the behavior of the consumption aggregate is modeled - for example, Verdelhan (2010), Colacito and Croce (2011), or Bansal and Shaliastovich (2013) - it is possible for the models cited above, in which preference differences are specified over individual tradable goods, or in which there are specific trade frictions over some goods.

\section{Conclusion}

Hansen and Jagannathan (1991) offer a powerful tool for constructing a lower bound on the variation of all agents' IMRSs. Their lower bound is constructed from a reduced-form SDF, which can be thought of as a common component of all agents' IMRSs, and relies only on asset return data and the assumption of no-arbitrage. Unfortunately, reduced-form SDFs, combined with asset return and exchange rate data, cannot be used in the same way to identify economically meaningful differences between agents' IMRSs.

Our positive message is that structural models - with explicit assumptions about preferences over goods, goods market frictions, or asset market imperfections - are necessary, and useful, to address specific questions about real exchange rate determination and risk sharing. We are certainly not the first to recognize this point. An early example is Backus and Smith (1993), who "examine the possibility that non-traded goods may account for several striking features of international macroeconomic data". In order to focus on this friction in the goods

replicated by defining it as the relative price of two different baskets of good 1 and good 2. See the Online Appendix. 
market, they assumed away frictions in the asset market (frictionless asset trading and complete markets). Their approach is in line with our main point. When the asset market view of exchange rates holds, variation in the real exchange rate only reflects frictions and/or preferences differences in the goods market. It does not reflect heterogeneity across agents in different economies in the compensation for risk they require to own various assets such as currencies.

\section{References}

Ahn, D.-H. 2004. Common Factors and Local Factors: Implications for Term Structures and Exchange Rates. Journal of Financial and Quantitative Analysis 39:69-102.

Anderson, B., P. J. Hammond, and C. A. Ramezani. 2010. Affine Models of the Joint Dynamics of Exchange Rates and Interest Rates. Journal of Financial and Quantitative Analysis 45:1341-1365.

Backus, D. K., S. Foresi, and C. I. Telmer. 2001. Affine Term Structure Models and the Forward Premium Anomaly. Journal of Finance 56.

Backus, D. K., and G. W. Smith. 1993. Consumption and real exchange rates in dynamic economies with non-traded goods. Journal of International Economics 35:297 - 316.

Bakshi, G., P. Carr, and L. Wu. 2008. Stochastic risk premiums, stochastic skewness in currency options, and stochastic discount factors in international economies. Journal of Financial Economics 87:132-156.

Bansal, R. 1997. An Exploration of the Forward Premium Puzzle in Currency Markets. The Review of Financial Studies 10:369-403.

Bansal, R., and I. Shaliastovich. 2013. A Long-Run Risks Explanation of Predictability Puzzles in Bond and Currency Markets. Review of Financial Studies 26:1-33.

Bekaert, G. 1996. The Time Variation of Risk and Return in Foreign Exchange Markets: A General Equilibrium Perspective. The Review of Financial Studies 9:427-470.

Black, F., and M. Scholes. 1973. The Pricing of Options and Corporate Liabilities. Journal of Political Economy 81:637-654. 
Brandt, M. W., J. H. Cochrane, and P. Santa-Clara. 2006. International risk sharing is better than you think, or exchange rates are too smooth. Journal of Monetary Economics 53:671-698.

Brandt, M. W., and P. Santa-Clara. 2002. Simulated likelihood estimation of diffusions with an application to exchange rate dynamics in incomplete markets. Journal of Financial Economics 63:161-210.

Brennan, M. J., and Y. Xia. 2006. International Capital Markets and Foreign Exchange Risk. The Review of Financial Studies 19:753-795.

Colacito, R., and M. M. Croce. 2011. Risks for the Long Run and the Real Exchange Rate. Journal of Political Economy 119:153-181.

Colacito, R., M. M. Croce, S. W. Ho, and P. Howard. 2018. BKK the EZ Way: International Long-Run Growth News and Capital Flows. American Economic Review 108:3416-3449.

Cox, J. C., S. A. Ross, and M. Rubinstein. 1979. Option pricing: A simplified approach. Journal of Financial Economics 7:229 - 263.

Dornbusch, R. 1976. Expectations and Exchange Rate Dynamics. Journal of Political Economy 84:1161-1176.

Frenkel, J. A. 1976. A Monetary Approach to the Exchange Rate: Doctrinal Aspects and Empirical Evidence. The Scandinavian Journal of Economics 78:200-224.

Hansen, L. P., and R. Jagannathan. 1991. Implications of Security Market Data for Models of Dynamic Economies. Journal of Political Economy 99:225-262.

Harrison, J., and D. M. Kreps. 1979. Martingales and arbitrage in multiperiod securities markets. Journal of Economic Theory 20:381-408.

Harrison, J., and S. R. Pliska. 1981. Martingales and stochastic integrals in the theory of continuous trading. Stochastic Processes and their Applications 11:215-260.

Harrison, J., and S. R. Pliska. 1983. A stochastic calculus model of continuous trading: Complete markets. Stochastic Processes and their Applications 15:313-316.

Karatzas, I., and C. Kardaras. 2007. The numéraire portfolio in semimartingale financial models. Finance \& Stochastics 11:447 - 493. 
Kouri, P. J. K. 1976. The Exchange Rate and the Balance of Payments in the Short Run and in the Long Run: A Monetary Approach. The Scandinavian Journal of Economics 78:280-304.

Long, J. B. 1990. The Numeraire Portfolio. Journal of Financial Economics 26:29-69.

Lustig, H., and A. Verdelhan. 2006. Investing in Foreign Currency is Like Betting on Your Intertemporal Marginal Rate of Substitution. Journal of the European Economic Association 4:644-655.

Lustig, H., and A. Verdelhan. 2007. The Cross Section of Foreign Currency Risk Premia and Consumption Growth Risk. The American Economic Review 97:89-117.

Lustig, H. N., N. L. Roussanov, and A. Verdelhan. 2011. Common Risk Factors in Currency Markets. Review of Financial Studies 24:3731-3777.

Lustig, H. N., N. L. Roussanov, and A. Verdelhan. 2014. Countercyclical Currency Risk Premia. Journal of Financial Economics 111:527-553.

Lustig, H. N., and A. Verdelhan. 2012. Exchange Rates in a Stochastic Discount Factor Framework. In J. James, I. Marsh, and L. Sarno (eds.), Handbook of Exchange Rates, Wiley Handbooks in Financial Engineering and Econometrics, chap. 14, pp. 391-420. Wiley.

Merton, R. C. 1973. Theory of Rational Option Pricing. The Bell Journal of Economics and Management Science 4:141-183.

Mussa, M. 1976. The Exchange Rate, the Balance of Payments and Monetary and Fiscal Policy under a Regime of Controlled Floating. The Scandinavian Journal of Economics $78: 229-248$.

Ready, R., N. Roussanov, and C. Ward. 2017. After the tide: Commodity currencies and global trade. Journal of Monetary Economics 85:69-86.

Smith, P., and M. Wickens. 2002. Asset Pricing with Observable Stochastic Discount Factors. Journal of Economic Surveys 16:397-446.

Stathopoulos, A. 2017. Asset Prices and Risk Sharing in Open Economies. Review of Financial Studies 30:363-415. 
Stockman, A. C. 1980. A Theory of Exchange Rate Determination. Journal of Political Economy 88:673-698.

Stockman, A. C., and L. L. Tesar. 1995. Tastes and Technology in a Two-Country Model of the Business Cycle: Explaining International Comovements. The American Economic Review 85:168-185.

Tesar, L. L. 1993. International risk-sharing and non-traded goods. Journal of International Economics 35:69-89.

Varian, H. R. 1984. Microeconomic Analysis. 2nd ed. W.W. Norton and Company.

Verdelhan, A. 2010. A Habit-Based Explanation of the Exchange Rate Risk Premium. The Journal of Finance 65:123-146. 


\section{Online Appendix}

In this appendix we outline an example of a full-fledged model of an endowment economy that is consistent with the discussion in Section 4 of the paper. The model is based on Backus and Smith (1993), and we use it to illustrate how aggregate consumption levels and the real exchange rate are jointly determined in equilibrium.

To make our notation compact we define the $n \times 1$ vectors $\boldsymbol{c}_{d}=\left(c_{d}^{1}, c_{d}^{2}, \cdots, c_{d}^{n}\right), \boldsymbol{c}_{f}=$ $\left(c_{f}^{1}, c_{f}^{2}, \cdots, c_{f}^{n}\right), \boldsymbol{P}_{d}=\left(1, P_{d}^{2}, \cdots, P_{d}^{n}\right)$ and $\boldsymbol{P}_{f}=\left(1, P_{f}^{2}, \cdots, P_{f}^{n}\right)$. We use a version of the model in which there are two periods, with time indexed by $t=0,1$. In the most general version of the model, asset markets are assumed to be incomplete, but we also explore a complete markets version of the model, as well as one with specific assumptions about the utility functions and consumption aggregators.

We assume that there are $k$ assets with $k \times 1$ random payoff vector $\boldsymbol{Z}(\omega)$ in period 1 , where $\omega \in \Omega$ represents the state of the world in period 1 , which has probability $\pi(\omega)$. We assume that $k$ is smaller than the number of states of the world, which is assumed to be finite. The $k \times 1$ price vector for these assets in period 0 is $\boldsymbol{P}_{\boldsymbol{Z}}$. The payoffs and prices of the assets are measured in units of good 1.

The domestic agent chooses $\boldsymbol{c}_{d, 0},\left\{\boldsymbol{c}_{d, 1}(\omega)\right\}_{\omega \in \Omega}$, and $\boldsymbol{a}_{d}$ to maximize

$$
u\left[c_{d}\left(\boldsymbol{c}_{d, 0}\right)\right]+\beta \sum_{\omega \in \Omega} u\left\{c_{d}\left[\boldsymbol{c}_{d, 1}(\omega)\right]\right\} \pi(\omega)
$$

subject to

$$
\begin{gathered}
\boldsymbol{P}_{d, 0} \cdot \boldsymbol{c}_{d, 0}+\boldsymbol{P}_{\boldsymbol{Z}} \cdot \boldsymbol{a}_{d}=\boldsymbol{P}_{d, 0} \cdot \boldsymbol{y}_{d, 0}, \\
\boldsymbol{P}_{d, 1}(\omega) \cdot \boldsymbol{c}_{d, 1}(\omega)=\boldsymbol{P}_{d, 1}(\omega) \cdot \boldsymbol{y}_{d, 1}(\omega)+\boldsymbol{Z}(\omega) \cdot \boldsymbol{a}_{d}, \quad \omega \in \Omega .
\end{gathered}
$$

Here $0<\beta<1, \boldsymbol{c}_{d, 0}$ is the agent's consumption vector at time $0, \boldsymbol{y}_{d, 0}$ is an $n \times 1$ vector of her endowments of the goods at time $0, \boldsymbol{c}_{d, 1}(\omega)$ are her plans for future consumption (in every possible state of the world), $\boldsymbol{y}_{d, 1}(\omega)$ are her future endowments (in every possible state of the world), and $\boldsymbol{a}_{d}$ is a $k \times 1$ vector whose $i$ th element is her net purchases of asset $i$.

Similarly, the foreign agent chooses $\boldsymbol{c}_{f, 0},\left\{\boldsymbol{c}_{f, 1}(\omega)\right\}_{\omega \in \Omega}$, and $\boldsymbol{a}_{f}$ to maximize

$$
u\left[c_{f}\left(\boldsymbol{c}_{f, 0}\right)\right]+\beta \sum_{\omega \in \Omega} u\left\{c_{f}\left[\boldsymbol{c}_{f, 1}(\omega)\right]\right\} \pi(\omega)
$$


subject to

$$
\begin{gathered}
\boldsymbol{P}_{f, 0} \cdot \boldsymbol{c}_{f, 0}+\boldsymbol{P}_{\boldsymbol{Z}} \cdot \boldsymbol{a}_{f}=\boldsymbol{P}_{f, 0} \cdot \boldsymbol{y}_{f, 0} \cdot \\
\boldsymbol{P}_{f, 1}(\omega) \cdot \boldsymbol{c}_{f, 1}(\omega)=\boldsymbol{P}_{f, 1}(\omega) \cdot \boldsymbol{y}_{f, 1}(\omega)+\boldsymbol{Z}(\omega) \cdot \boldsymbol{a}_{f}, \quad \omega \in \Omega .
\end{gathered}
$$

For simplicity, we assume that each good is either frictionlessly traded across economies or is not traded across economies. The market clearing conditions for any frictionlessly traded good, $j$, are

$$
\begin{aligned}
c_{d, 0}^{j}+c_{f, 0}^{j} & =y_{d, 0}^{j}+y_{f, 0}^{j}, \\
c_{d, 1}^{j}(\omega)+c_{f, 1}^{j}(\omega) & =y_{d, 1}^{j}(\omega)+y_{f, 1}^{j}(\omega), \quad \omega \in \Omega .
\end{aligned}
$$

For a nontraded good, $j$, we have

$$
\begin{aligned}
c_{d, 0}^{j} & =y_{d, 0}^{j}, \quad c_{f, 0}^{j}=y_{f, 0}^{j}, \\
c_{d, 1}^{j}(\omega) & =y_{d, 1}^{j}(\omega), \quad c_{f, 1}^{j}(\omega)=y_{f, 1}^{j}(\omega), \quad \omega \in \Omega .
\end{aligned}
$$

The market clearing condition in the asset market is

$$
\boldsymbol{a}_{d}+\boldsymbol{a}_{f}=\mathbf{0}
$$

Definition. A competitive equilibrium is a set of vectors of quantities $\boldsymbol{c}_{d, 0}, \boldsymbol{c}_{f, 0},\left\{\boldsymbol{c}_{d, 1}(\omega)\right\}_{\omega \in \Omega}$, $\left\{\boldsymbol{c}_{f, 1}(\omega)\right\}_{\omega \in \Omega}, \boldsymbol{a}_{d}, \boldsymbol{a}_{f}$, and prices $\boldsymbol{P}_{d, 0}, \boldsymbol{P}_{f, 0},\left\{\boldsymbol{P}_{d, 1}(\omega)\right\}_{\omega \in \Omega},\left\{\boldsymbol{P}_{f, 1}(\omega)\right\}_{\omega \in \Omega}, \boldsymbol{P}_{\boldsymbol{Z}}$ such that the quantities solve the agents' optimization problems (taking the prices as given), and such that the market clearing conditions are satisfied. The law of one price must hold for any good that is frictionlessly traded.

The first order conditions for the domestic agent are

$$
\begin{gathered}
u_{c}\left[c_{d}\left(\boldsymbol{c}_{d, 0}\right)\right] \frac{d c_{d}\left(\boldsymbol{c}_{d, 0}\right)}{d \boldsymbol{c}_{d, 0}}=\boldsymbol{P}_{d, 0} \lambda_{d}, \\
\beta u_{c}\left\{c_{d}\left[\boldsymbol{c}_{d, 1}(\omega)\right]\right\} \frac{d c_{d}\left[\boldsymbol{c}_{d, 1}(\omega)\right]}{d \boldsymbol{c}_{d, 1}(\omega)} \pi(\omega)=\boldsymbol{P}_{d, 1}(\omega) \mu_{d}(\omega), \quad \omega \in \Omega . \\
\boldsymbol{P}_{\boldsymbol{Z}} \lambda_{d}=\sum_{\omega \in \Omega} \mu_{d}(\omega) \boldsymbol{Z}(\omega) .
\end{gathered}
$$

Here $\lambda_{d}$ is the Lagrange multiplier on the constraint (43), and $\mu_{d}(\omega)$ is the Lagrange multiplier on the constraint (44). 
The first order conditions for the foreign agent are

$$
\begin{gathered}
u_{c}\left[c_{f}\left(\boldsymbol{c}_{f, 0}\right)\right] \frac{d c_{f}\left(\boldsymbol{c}_{f, 0}\right)}{d \boldsymbol{c}_{f, 0}}=\boldsymbol{P}_{f, 0} \lambda_{f}, \\
\beta u_{c}\left\{c_{f}\left[\boldsymbol{c}_{f, 1}(\omega)\right]\right\} \frac{d c_{f}\left[\boldsymbol{c}_{f, 1}(\omega)\right]}{d \boldsymbol{c}_{f, 1}(\omega)} \pi(\omega)=\boldsymbol{P}_{f, 1}(\omega) \mu_{f}(\omega), \quad \omega \in \Omega . \\
\boldsymbol{P}_{\boldsymbol{Z}} \lambda_{f}=\sum_{\omega \in \Omega} \mu_{f}(\omega) \boldsymbol{Z}(\omega) .
\end{gathered}
$$

Here $\lambda_{f}$ is the Lagrange multiplier on the constraint (46), and $\mu_{f}(\omega)$ is the Lagrange multiplier on the constraint (47).

Consider the first order conditions for the numeraire good in periods 0 and 1 . If we combine these we get an expression for the IMRSs in the numeraire good::

$$
\begin{aligned}
& M_{d}^{1}(\omega) \equiv \frac{\beta u_{c}\left\{c_{d}\left[\boldsymbol{c}_{d, 1}(\omega)\right]\right\} \frac{d c_{d}\left[\boldsymbol{c}_{d, 1}(\omega)\right]}{d c_{d, 1}^{1}(\omega)}}{u_{c}\left[c_{d}\left(\boldsymbol{c}_{d, 0}\right)\right] \frac{d c_{d}\left(\boldsymbol{c}_{d, 0}\right)}{d c_{d, 0}^{1}}}=\frac{\mu_{d}(\omega)}{\lambda_{d} \pi(\omega)}, \quad \omega \in \Omega, \\
& M_{f}^{1}(\omega) \equiv \frac{\beta u_{c}\left\{c_{f}\left[\boldsymbol{c}_{f, 1}(\omega)\right]\right\} \frac{d c_{f}\left[\boldsymbol{c}_{f, 1}(\omega)\right]}{d c_{f, 1}^{\prime}(\omega)}}{u_{c}\left[c_{f}\left(\boldsymbol{c}_{f, 0}\right)\right] \frac{d c_{f}\left(\boldsymbol{c}_{f, 0}\right)}{d c_{f, 0}}}=\frac{\mu_{f}(\omega)}{\lambda_{f} \pi(\omega)}, \quad \omega \in \Omega .
\end{aligned}
$$

We define the ratio between these IMRSs as

$$
\Xi(\omega) \equiv \frac{M_{f}^{1}(\omega)}{M_{d}^{1}(\omega)}=\left[\frac{\mu_{f}(\omega)}{\lambda_{f}}\right] /\left[\frac{\mu_{d}(\omega)}{\lambda_{d}}\right] .
$$

For any other good we have the IMRSs:

$$
\begin{gathered}
M_{d}^{j}(\omega) \equiv \frac{\beta u_{c}\left\{c_{d}\left[\boldsymbol{c}_{d, 1}(\omega)\right]\right\} \frac{d c_{d}\left[\boldsymbol{c}_{d, 1}(\omega)\right]}{d c_{d, 1}^{j}(\omega)}}{u_{c}\left(c_{d}\left(\boldsymbol{c}_{d, 0}\right)\right) \frac{d c_{d}\left(\boldsymbol{c}_{d, 0}\right)}{d c_{d, 0}^{j}}}=\frac{P_{d, 1}^{j}(\omega)}{P_{d, 0}^{j}} \frac{\mu_{d}(\omega)}{\lambda_{d} \pi(\omega)}, \quad \omega \in \Omega, \\
M_{f}^{j}(\omega) \equiv \frac{\beta u_{c}\left\{c_{f}\left[\boldsymbol{c}_{f, 1}(\omega)\right]\right\} \frac{d c_{f}\left[\boldsymbol{c}_{f, 1}(\omega)\right]}{d c_{f, 1}^{j}(\omega)}}{u_{c}\left(c_{f}\left(\boldsymbol{c}_{f, 0}\right)\right) \frac{d c_{f}\left(\boldsymbol{c}_{f, 0}\right)}{d c_{f, 0}^{j}}}=\frac{P_{f, 1}^{j}(\omega)}{P_{f, 0}^{j}} \frac{\mu_{f}(\omega)}{\lambda_{f} \pi(\omega)}, \quad \omega \in \Omega .
\end{gathered}
$$

For any frictionlessly traded good, because the law of one price holds, we have

$$
\frac{M_{f}^{j}(\omega)}{M_{d}^{j}(\omega)}=\Xi(\omega)
$$


For nontraded goods we have

$$
\frac{M_{f}^{j}(\omega)}{M_{d}^{j}(\omega)}=\Xi(\omega) \frac{P_{f, 1}^{j}(\omega) / P_{f, 0}^{j}}{P_{d, 1}^{j}(\omega) / P_{d, 0}^{j}}
$$

\section{Complete Asset Markets}

When asset markets are complete we can assume that there is a complete set of state contingent claims. That is, we can assume that there are $k$ states of the world (just as there are $k$ assets) and that the payoff on asset $i$ in state $\omega=i$ is 1 and is zero otherwise. ${ }^{19}$ This means that Eqs. (55) and (58) are equivalent to

$$
\begin{gathered}
\boldsymbol{P}_{\boldsymbol{Z}} \lambda_{d}=\boldsymbol{\mu}_{d}, \\
\boldsymbol{P}_{\boldsymbol{Z}} \lambda_{f}=\boldsymbol{\mu}_{f},
\end{gathered}
$$

where $\boldsymbol{\mu}_{d}=\left[\mu_{d}(1), \ldots, \mu_{d}(k)\right]$ and $\boldsymbol{\mu}_{f}=\left[\mu_{f}(1), \ldots, \mu_{f}(k)\right]$. This means that when asset markets are complete we have

$$
\frac{\boldsymbol{\mu}_{d}}{\lambda_{d}}=\frac{\boldsymbol{\mu}_{f}}{\lambda_{f}} .
$$

Consequently, when asset markets are complete, we have the result that $\Xi(\omega)=1$ for all $\omega$,

$$
\frac{M_{f}^{j}(\omega)}{M_{d}^{j}(\omega)}=\Xi(\omega)=1,
$$

for any frictionlessly traded good, and

$$
\frac{M_{f}^{j}(\omega)}{M_{d}^{j}(\omega)}=\frac{P_{f, 1}^{j}(\omega) / P_{f, 0}^{j}}{P_{d, 1}^{j}(\omega) / P_{d, 0}^{j}}
$$

for any nontraded good.

\footnotetext{
${ }^{19}$ To see this, suppose that there are $k$ states of the world. We can arrange the payoff vectors in a matrix $\mathcal{Z}$ whose $i$ th row is $\boldsymbol{Z}(i)^{\prime}$. If asset markets are complete the matrix $\mathcal{Z}$ is invertible. This means that $\tilde{\boldsymbol{P}}_{\boldsymbol{Z}}=\left(\mathcal{Z}^{-1}\right)^{\prime} \boldsymbol{P}_{\boldsymbol{Z}}$ is the price vector corresponding to a set of state contingent claims that can be formed as portfolios of the original assets. The contingent claim for state $\omega$ is equivalent to a portfolio of the original assets with the portfolio weights being given by the $\omega$ th column of $Z^{-1}$.
} 


\section{Price Indices and the Real Exchange Rate}

Given a particular set of prices for the individual goods, we can solve the domestic agent's static expenditure minimization problem

$$
\min _{\boldsymbol{c}_{d, 1}} \boldsymbol{P}_{d} \cdot \boldsymbol{c}_{d} \quad \text { subject to } \quad c_{d}=c_{d}\left(\boldsymbol{c}_{d}\right)
$$

Because $c_{d}(\cdot)$ is a homogenous of degree one function, minimized expenditure is equal to $P_{d} c_{d}$ where $P_{d}=H_{d}\left(\boldsymbol{P}_{d}\right)$, with $H_{d}(\cdot)$ also being homogenous of degree one in its arguments, and having a form related to the function $c_{d}(\cdot)$ (see Varian, 1984). Similarly, the foreign price index is $P_{f}=H_{f}\left(\boldsymbol{P}_{f}\right)$. Since all prices are measured in the same numeraire, the real exchange rate is $e \equiv P_{f} / P_{d}$.

In the special case where $c_{d}(\cdot)=c_{f}(\cdot)$, we have $H_{d}(\cdot)=H_{f}(\cdot)$. If, additionally, all goods are frictionlessly traded, $e=1$. If preferences differ across countries and all goods are

frictionlessly traded, variation in the real exchange rate can arise even though $P_{d}^{j}=P_{f}^{j}$ for all $j$.

\section{Aggregate IMRSs}

Eqs. (53) and (54) imply

$$
\begin{gathered}
u_{c}\left[c_{d}\left(\boldsymbol{c}_{d, 0}\right)\right]\left[\frac{d c_{d}\left(\boldsymbol{c}_{d, 0}\right)}{d \boldsymbol{c}_{d, 0}} \cdot \boldsymbol{c}_{d, 0}\right]=\lambda_{d}\left[\boldsymbol{c}_{d, 0} \cdot \boldsymbol{P}_{d, 0}\right], \\
\beta u_{c}\left\{c_{d}\left[\boldsymbol{c}_{d, 1}(\omega)\right]\right\}\left[\frac{d c_{d}\left[\boldsymbol{c}_{d, 1}(\omega)\right]}{d \boldsymbol{c}_{d, 1}(\omega)} \cdot \boldsymbol{c}_{d, 1}(\omega)\right] \pi(\omega)=\left[\boldsymbol{c}_{d, 1}(\omega) \cdot \boldsymbol{P}_{d, 1}(\omega)\right] \mu_{d}(\omega), \quad \omega \in \Omega .
\end{gathered}
$$

Because $\boldsymbol{c}_{d, 0} \cdot \boldsymbol{P}_{d, 0}=c_{d, 0} P_{d, 0}, \boldsymbol{c}_{d, 1}(\omega) \cdot \boldsymbol{P}_{d, 1}(\omega)=c_{d, 1}(\omega) \cdot P_{d, 1}(\omega)$, and $c_{d}(\cdot)$ is homogenous of degree 1 , this means we can rewrite these two Eqs. as

$$
\begin{gathered}
u_{c}\left[c_{d}\left(\boldsymbol{c}_{d, 0}\right)\right]=P_{d, 0} \lambda_{d}, \\
\beta u_{c}\left\{c_{d}\left[\boldsymbol{c}_{d, 1}(\omega)\right]\right\} \pi(\omega)=P_{d, 1}(\omega) \mu_{d}(\omega), \quad \omega \in \Omega .
\end{gathered}
$$

It follows that the IMRS over aggregate consumption for the domestic agent is

$$
M_{d}(\omega) \equiv \beta \frac{u_{c}\left\{c_{d}\left[\boldsymbol{c}_{d, 1}(\omega)\right]\right\}}{u_{c}\left[c_{d}\left(\boldsymbol{c}_{d, 0}\right)\right]}=\frac{P_{d, 1}(\omega)}{P_{d, 0}} \frac{\mu_{d}(\omega)}{\lambda_{d} \pi(\omega)}, \quad \omega \in \Omega
$$


Similarly, for the foreign agent, the IMRS over aggregate consumption is

$$
M_{f}^{*}(\omega) \equiv \beta \frac{u_{c}\left\{c_{f}\left[\boldsymbol{c}_{f, 1}(\omega)\right]\right\}}{u_{c}\left[c_{f}\left(\boldsymbol{c}_{f, 0}\right)\right]}=\frac{P_{f, 1}(\omega)}{P_{f, 0}} \frac{\mu_{f}(\omega)}{\lambda_{f} \pi(\omega)}, \quad \omega \in \Omega .
$$

We use the $*$ notation for the foreign agent to emphasize that the agents' consumption aggregators are different.

Together. Eqs. (72) and (73) imply that

$$
\frac{M_{f}^{*}(\omega)}{M_{d}(\omega)}=\left[\frac{P_{f, 1}(\omega)}{P_{f, 0}} \frac{\mu_{f}(\omega)}{\lambda_{f}}\right] /\left[\frac{P_{d, 1}(\omega)}{P_{d, 0}} \frac{\mu_{d}(\omega)}{\lambda_{d}}\right]=\frac{e_{1}(\omega)}{e_{0}} \Xi(\omega) .
$$

Letting $X(\omega)=e_{1}(\omega) / e_{0}$ we can rewrite Eq. (74) as

$$
\frac{M_{f}^{*}(\omega)}{M_{d}(\omega)}=X(\omega) \Xi(\omega)
$$

\section{A Specific Model Under Complete Markets}

We adopt the following assumptions: (1) There are two goods, 1 and 2, with good 1 being the numeraire, and being frictionlessly traded. (2) $u(\cdot)=\ln (\cdot),(3) c_{d}\left(c_{d}^{1}, c_{d}^{2}\right)=\left(c_{d}^{1}\right)^{\theta_{d}}\left(c_{d}^{2}\right)^{1-\theta_{d}}$ and $c_{f}\left(c_{f}^{1}, c_{f}^{2}\right)=\left(c_{f}^{1}\right)^{\theta_{f}}\left(c_{f}^{2}\right)^{1-\theta_{f}}$. These assumptions imply that the CPIs in the two countries, measured in units of good 1 , are

$$
P_{d}=\rho_{d}\left(P_{d}^{2}\right)^{1-\theta_{d}}, \quad \text { and } \quad P_{f}=\rho_{f}\left(P_{f}^{2}\right)^{1-\theta_{f}}
$$

with $\rho_{d}=\theta_{d}^{-\theta_{d}}\left(1-\theta_{d}\right)^{\theta_{d}-1}$, and $\rho_{f}=\theta_{f}^{-\theta_{f}}\left(1-\theta_{f}\right)^{\theta_{f}-1}$. The real exchange rate is

$$
e=\left(\rho_{f} / \rho_{d}\right)\left[\left(P_{f}^{2}\right)^{1-\theta_{f}} /\left(P_{d}^{2}\right)^{1-\theta_{d}}\right]
$$

We discuss two specific examples of our model, which assume, alternatively, that good 2 is frictionlessly traded or nontraded. We use the following notation, and henceforth drop the notational dependence of time 1 variables on $\omega$ unless it is needed. The global endowment of good $j$ in period $t$ is $Y_{t}^{j}=y_{d t}^{j}+y_{f t}^{j}, j=1,2$. The growth rates of the global endowments of $\operatorname{good} j$ is $G^{j}=Y_{1}^{j} / Y_{0}^{j}, j=1,2$. We also define $g_{d}^{j}=y_{d, 1}^{j} / y_{d, 0}^{j}$ and $g_{f}^{j}=y_{f, 1}^{j} / y_{f, 0}^{j}, j=1,2$. The domestic agent's share of the global endowment of good $j$ at time $t$ is $s_{t}^{j}=y_{d t}^{j} / Y_{t}^{j}$, $j=1,2$. We let $\bar{s}_{1}^{j}=\sum_{\omega} s_{1}^{j}(\omega) \pi(\omega), j=1,2$, denote the domestic agent's expected shares of the global endowments in period 1. 
With the above assumptions the first order conditions for the two agents can be written as

$$
\begin{gathered}
\theta_{d} / c_{d, 0}^{1}=\lambda_{d}, \\
\left(1-\theta_{d}\right) / c_{d, 0}^{2}=P_{d, 0}^{2} \lambda_{d}, \\
\beta\left[\theta_{d} / c_{d, 1}^{1}(\omega)\right] \pi(\omega)=\mu_{d}(\omega), \quad \omega \in \Omega . \\
\beta\left[\left(1-\theta_{d}\right) / c_{d, 1}^{2}(\omega)\right] \pi(\omega)=P_{d, 1}^{2}(\omega) \mu_{d}(\omega), \quad \omega \in \Omega . \\
P_{Z}(\omega) \lambda_{d}=\mu_{d}(\omega), \quad \omega \in \Omega . \\
\left(1-\theta_{f}\right) / c_{f, 0}^{2}=P_{f, 0}^{2} \lambda_{f}, \\
\beta\left[\theta_{f} / c_{f, 1}^{1}(\omega)\right] \pi(\omega)=\mu_{f}(\omega), \quad \omega \in \Omega . \\
\left.\left.\theta_{f}\right) / c_{f, 1}^{2}(\omega)\right] \pi(\omega)=P_{f, 1}^{2}(\omega) \mu_{f}(\omega), \quad \omega \in \Omega . \\
P_{Z}(\omega) \lambda_{f}=\mu_{f}(\omega), \quad \omega \in \Omega .
\end{gathered}
$$

To solve the model we also use the domestic agent's lifetime budget constraint:

$$
\begin{aligned}
c_{d, 0}^{1}+P_{d, 0}^{2} c_{d, 0}^{2}+ & \sum_{\omega} P_{Z}(\omega)\left[c_{d, 1}^{1}(\omega)+P_{d, 1}^{2}(\omega) c_{d, 1}^{2}(\omega)\right]= \\
& y_{d, 0}^{1}+P_{d, 0}^{2} y_{d, 0}^{2}+\sum_{\omega} P_{Z}(\omega)\left[y_{d, 1}^{1}(\omega)+P_{d, 1}^{2}(\omega) y_{d, 1}^{2}(\omega)\right]
\end{aligned}
$$

Both Goods are Frictionlessly Traded. When both goods are frictionlessly traded, we drop location subscripts from the price of good 2, and we write the market clearing conditions for goods as

$$
\begin{gathered}
c_{d, 0}^{1}+c_{f, 0}^{1}=Y_{0}^{1} \\
c_{d, 1}^{1}(\omega)+c_{f, 1}^{1}(\omega)=Y_{1}^{1}(\omega) \\
c_{d, 0}^{2}+c_{f, 0}^{2}=Y_{0}^{2} \\
c_{d, 1}^{2}(\omega)+c_{f, 1}^{2}(\omega)=Y_{1}^{2}(\omega)
\end{gathered}
$$

To solve the model we let eliminate unknowns by solving for them in terms of the domestic agent's expenditure at time 0 , which we denote $F_{d}=c_{d, 0}^{1}+P_{0}^{2} c_{d, 0}^{2}$. We denote the foreign agent's expenditure at time 0 as $F_{f}=c_{f, 0}^{1}+P_{0}^{2} c_{f, 0}^{2}$. Eqs. (78) and (79) imply that $F_{d}=\lambda_{d}^{-1}$, 
while Eqs. (83) and (84) imply that $F_{f}=\lambda_{d}^{-1}$. These results together with Eqs. (82) and (82) allow us to rewrite Eqs. (78)-(81) and (83)-(86) as

$$
\begin{gathered}
c_{d, 0}^{1}=\theta_{d} F_{d} . \\
c_{d, 0}^{2} P_{0}^{2}=\left(1-\theta_{d}\right) F_{d}, \\
c_{d, 1}^{1}(\omega)=\beta \theta_{d} \frac{\pi(\omega)}{P_{Z}(\omega)} F_{d}, \quad \omega \in \Omega . \\
c_{d, 1}^{2}(\omega) P_{1}^{2}(\omega)=\beta\left(1-\theta_{d}\right) \frac{\pi(\omega)}{P_{Z}(\omega)} F_{d}, \quad \omega \in \Omega . \\
c_{f, 0}^{1}=\theta_{f} F_{f} . \\
c_{f, 0}^{2} P_{0}^{2}=\left(1-\theta_{f}\right) F_{f}, \\
c_{f, 1}^{1}(\omega)=\beta \theta_{f} \frac{\pi(\omega)}{P_{Z}(\omega)} F_{f}, \quad \omega \in \Omega . \\
c_{f, 1}^{2}(\omega) P_{1}^{2}(\omega)=\beta\left(1-\theta_{f}\right) \frac{\pi(\omega)}{P_{Z}(\omega)} F_{f}, \quad \omega \in \Omega .
\end{gathered}
$$

If we substitute these results into the market clearing conditions we get

$$
\begin{gathered}
\theta_{d} F_{d}+\theta_{f} F_{f}=Y_{0}^{1} \\
\beta \frac{\pi(\omega)}{P_{Z}(\omega)}\left(\theta_{d} F_{d}+\theta_{f} F_{f}\right)=Y_{1}^{1}(\omega) \\
{\left[\left(1-\theta_{d}\right) F_{d}+\left(1-\theta_{f}\right) F_{f}\right] / P_{0}^{2}=Y_{0}^{2}} \\
\beta \frac{\pi(\omega)}{P_{Z}(\omega)}\left[\left(1-\theta_{d}\right) F_{d}+\left(1-\theta_{f}\right) F_{f}\right] / P_{1}^{2}(\omega)=Y_{1}^{2}(\omega)
\end{gathered}
$$

Eq. (101) implies

$$
F_{f}=\frac{1}{\theta_{f}}\left(Y_{0}^{1}-\theta_{d} F_{d}\right)
$$

Eqs. (103) and (105)

$$
P_{0}^{2}=\frac{\left(1-\theta_{d}\right) F_{d}+\left(1-\theta_{f}\right) F_{f}}{Y_{0}^{2}}=\frac{\frac{\theta_{f}-\theta_{d}}{\theta_{f}} F_{d}+\frac{1-\theta_{f}}{\theta_{f}} Y_{0}^{1}}{Y_{0}^{2}}
$$


Eqs. (101) and (102) together imply

$$
P_{Z}(\omega)=\beta \frac{\pi(\omega)}{G^{1}(\omega)} .
$$

Eq. (104), (103) and (107) imply

$$
P_{1}^{2}(\omega)=\beta \frac{\pi(\omega)}{P_{Z}(\omega)} \frac{Y_{0}^{2}}{Y_{1}^{2}(\omega)} P_{0}^{2}=\frac{G^{1}(\omega)}{G^{2}(\omega)} P_{0}^{2} .
$$

Because the price of good 2 is the same in both economies, from Eq. (77) we can see that the logarithm of the real exchange rate in each period is just $\ln e=\ln \left(\rho_{f} / \rho_{d}\right)+\left(\theta_{d}-\theta_{f}\right) \ln \left(P^{2}\right)$. Hence, from Eq. (108), the log change in the real exchange rate is

$$
\ln X(\omega)=\left(\theta_{f}-\theta_{d}\right) \ln \left[G^{2}(\omega) / G^{1}(\omega)\right] .
$$

All that remains is to solve for $F_{d}$. We can do this by substituting Eqs. (93)-(96) into Eq. (88) while using the notation $s_{t}^{j}=y_{d t}^{j} / Y_{t}^{j}$ to get

$$
(1+\beta) F_{d}=s_{0}^{1} Y_{0}^{1}+P_{0}^{2} s_{0}^{2} Y_{0}^{2}+\sum_{\omega} P_{Z}(\omega)\left[s_{1}^{1}(\omega) Y_{1}^{1}(\omega)+P_{1}^{2}(\omega) s_{1}^{2}(\omega) Y_{1}^{2}(\omega)\right]
$$

Using Eqs. (106), (107) and (108), we end up with

$$
F_{d}=\frac{\theta_{f}\left(s_{0}^{1}+\beta \bar{s}_{1}^{1}\right)+\left(1-\theta_{f}\right)\left(s_{0}^{2}+\beta \bar{s}_{1}^{2}\right)}{\theta_{f}(1+\beta)+\left(\theta_{d}-\theta_{f}\right)\left(s_{0}^{2}+\beta \bar{s}_{1}^{2}\right)} Y_{0}^{1}
$$

By substitution of this result into Eqs. (105) and (106), we get

$$
\begin{gathered}
F_{f}=\frac{\theta_{d}\left[\left(1-s_{0}^{1}\right)+\beta\left(1-\bar{s}_{1}^{1}\right)\right]+\left(1-\theta_{d}\right)\left[\left(1-s_{0}^{2}\right)+\beta\left(1-\bar{s}_{1}^{2}\right)\right]}{\theta_{f}(1+\beta)+\left(\theta_{d}-\theta_{f}\right)\left(s_{0}^{2}+\beta \bar{s}_{1}^{2}\right)} Y_{0}^{1} \\
P_{0}^{2}=\frac{\left(1-\theta_{f}\right)(1+\beta)+\left(\theta_{f}-\theta_{d}\right)\left(s_{0}^{1}+\beta \bar{s}_{1}^{1}\right)}{\theta_{f}(1+\beta)+\left(\theta_{d}-\theta_{f}\right)\left(s_{0}^{2}+\beta \bar{s}_{1}^{2}\right)} \frac{Y_{0}^{1}}{Y_{0}^{2}}
\end{gathered}
$$

Given the form of the utility function, domestic aggregate consumption growth is

$$
\ln \left[c_{d, 1}(\omega) / c_{d, 0}\right]=\theta_{d} \ln \left[c_{d, 1}^{1}(\omega) / c_{d, 0}^{1}\right]+\left(1-\theta_{d}\right) \ln \left[c_{d, 1}^{2}(\omega) / c_{d, 0}^{2}\right]
$$


Given Eqs. (93)-(96) and (106)-(108) we have

$$
\begin{aligned}
& c_{d, 1}^{1}(\omega) / c_{d, 0}^{1}=G^{1}(\omega), \quad \omega \in \Omega . \\
& c_{d, 1}^{2}(\omega) / c_{d, 0}^{2}=G^{2}(\omega), \quad \omega \in \Omega .
\end{aligned}
$$

Hence, Eq. (114) can be rewritten as

$$
\ln \left[c_{d, 1}(\omega) / c_{d, 0}\right]=\theta_{d} \ln G^{1}(\omega)+\left(1-\theta_{d}\right) \ln G^{2}(\omega)
$$

Similarly, for the foreign agent, aggregate consumption growth is

$$
\ln \left[c_{f, 1}(\omega) / c_{f, 0}\right]=\theta_{f} \ln G^{1}(\omega)+\left(1-\theta_{f}\right) \ln G^{2}(\omega)
$$

One Good is Not Traded. We now assume that it is not possible to trade good 2 between the two economies. Thus, we replace the market clearing conditions for good 2, (91) and (92), with the following equations:

$$
\begin{gathered}
c_{d, 0}^{2}=y_{d, 0}^{2}, \quad c_{f, 0}^{2}=y_{f, 0}^{2} \\
c_{d, 1}^{2}(\omega)=y_{d, 1}^{2}(\omega), \quad c_{f, 1}^{2}(\omega)=y_{f, 1}^{2}(\omega)
\end{gathered}
$$

We also assume, as in the main text, that $\theta_{d}=\theta_{f}=\theta$. After noting that the price of good 2 now requires a location subscript, if we substitute Eqs. (93)-(100) into the market clearing conditions we get

$$
\begin{gathered}
\theta\left(F_{d}+F_{f}\right)=Y_{0}^{1} \\
\beta \frac{\pi(\omega)}{P_{Z}(\omega)} \theta\left(F_{d}+F_{f}\right)=Y_{1}^{1}(\omega) \\
(1-\theta) F_{d} / P_{d, 0}^{2}=y_{d, 0}^{2} \\
(1-\theta) F_{f} / P_{f, 0}^{2}=y_{f, 0}^{2} \\
\beta \frac{\pi(\omega)}{P_{Z}(\omega)}(1-\theta) F_{d} / P_{d, 1}^{2}(\omega)=y_{d, 1}^{2}(\omega) \\
\beta \frac{\pi(\omega)}{P_{Z}(\omega)}(1-\theta) F_{f} / P_{f, 1}^{2}(\omega)=y_{f, 1}^{2}(\omega)
\end{gathered}
$$

Eq. (121) implies

$$
F_{f}=Y_{0}^{1} / \theta-F_{d}
$$


Eq. (123) implies that

$$
P_{d, 0}^{2}=\frac{\left(1-\theta_{d}\right) F_{d}}{y_{d, 0}^{2}}
$$

while Eqs. (124) and (127) imply that

$$
P_{f, 0}^{2}=\frac{(1-\theta) F_{f}}{y_{f, 0}^{2}}=\frac{(1-\theta)\left[Y_{0}^{1} / \theta-F_{d}\right]}{y_{f, 0}^{2}}
$$

Eqs. (121) and (122) together imply

$$
P_{Z}(\omega)=\beta \frac{\pi(\omega)}{G^{1}(\omega)}
$$

Eqs. (125), (123) and (130) imply

$$
P_{d, 1}^{2}(\omega)=\beta \frac{\pi(\omega)}{P_{Z}(\omega)} \frac{y_{d, 0}^{2}}{y_{d, 1}^{2}(\omega)} P_{d, 0}^{2}=\frac{G^{1}(\omega)}{g_{d}^{2}(\omega)} P_{d, 0}^{2} .
$$

Eqs. (126), (124) and (130) imply

$$
P_{f, 1}^{2}(\omega)=\beta \frac{\pi(\omega)}{P_{Z}(\omega)} \frac{y_{f, 0}^{2}}{y_{f, 1}^{2}(\omega)} P_{f, 0}^{2}=\frac{G^{1}(\omega)}{g_{f}^{2}(\omega)} P_{f, 0}^{2} .
$$

Because agents have the same preferences, from Eq. (77) we can see that the logarithm of the real exchange rate in each period is $\ln e=(1-\theta) \ln \left(P_{f}^{2} / P_{d}^{2}\right)$. Hence, from Eqs. (131) and (132) the log change in the real exchange rate is

$$
\ln X(\omega)=(1-\theta)\left[\ln g_{d}^{2}(\omega)-\ln g_{f}^{2}(\omega)\right]
$$

All that remains is to solve for $F_{d}$. In the lifetime budget constraint, Eq. (88), if we use Eqs. (119) and (120), the terms involving the nontraded good cancel out from either side of the equation. We can then use Eqs. (93), (95), and the notation $s_{t}^{1}=y_{d t}^{1} / Y_{t}^{1}$, to rewrite Eq. (88) as

$$
\theta(1+\beta) F_{d}=s_{0}^{1} Y_{0}^{1}+\sum_{\omega} P_{Z}(\omega)\left[s_{1}^{1}(\omega) Y_{1}^{1}(\omega)\right]
$$

Using Eq. (130), we end up with

$$
F_{d}=\frac{s_{0}^{1}+\beta \bar{s}_{1}^{1}}{\theta(1+\beta)} Y_{0}^{1}
$$


By substitution of this result into Eqs. (127), (128) and (129) we get

$$
\begin{gathered}
F_{f}=\frac{\left(1-s_{0}^{1}\right)+\beta\left(1-\bar{s}_{1}^{1}\right)}{\theta(1+\beta)} Y_{0}^{1} \\
P_{d, 0}^{2}=\frac{1-\theta}{\theta} \frac{s_{0}^{1}+\beta \bar{s}_{1}^{1}}{1+\beta} \frac{Y_{0}^{1}}{y_{d, 0}^{2}} \\
P_{f, 0}^{2}=\frac{1-\theta}{\theta} \frac{\left(1-s_{0}^{1}\right)+\beta\left(1-\bar{s}_{1}^{1}\right)}{1+\beta} \frac{Y_{0}^{1}}{y_{f, 0}^{2}}
\end{gathered}
$$

Given the form of the utility function, domestic aggregate consumption growth is

$$
\ln \left[c_{d, 1}(\omega) / c_{d, 0}\right]=\theta \ln \left[c_{d, 1}^{1}(\omega) / c_{d, 0}^{1}\right]+(1-\theta) \ln \left[c_{d, 1}^{2}(\omega) / c_{d, 0}^{2}\right]
$$

Given Eqs. (93), (95), (130), (119), and (120) we have

$$
\begin{aligned}
& c_{d, 1}^{1}(\omega) / c_{d, 0}^{1}=G^{1}(\omega), \quad \omega \in \Omega . \\
& c_{d, 1}^{2}(\omega) / c_{d, 0}^{2}=g_{d}^{2}(\omega), \quad \omega \in \Omega .
\end{aligned}
$$

Hence, Eq. (139) can be rewritten as

$$
\ln \left[c_{d, 1}(\omega) / c_{d, 0}\right]=\theta \ln G^{1}(\omega)+(1-\theta) \ln g_{d}^{2}(\omega)
$$

Similarly, for the foreign agent, aggregate consumption growth is

$$
\ln \left[c_{f, 1}(\omega) / c_{f, 0}\right]=\theta \ln G^{1}(\omega)+(1-\theta) \ln g_{f}^{2}(\omega)
$$

A Representative Agent Model. We now consider a model with a single representative agent whose preferences have the same functional form as in the previous examples, and whose endowments correspond to the global endowments of the two goods. The agent also has access to a complete set of state contingent claims. Letting $F$ be the agent's expenditure on consumption in period 0 , and letting $\theta$ be the weight on good 1 in the utility function, we can write the first order conditions as

$$
\begin{gathered}
c_{0}^{1}=\theta F . \\
c_{0}^{2} P_{0}^{2}=(1-\theta) F,
\end{gathered}
$$




$$
\begin{aligned}
c_{1}^{1}(\omega) & =\beta \theta \frac{\pi(\omega)}{P_{Z}(\omega)} F, \quad \omega \in \Omega . \\
c_{1}^{2}(\omega) P_{1}^{2}(\omega) & =\beta(1-\theta) \frac{\pi(\omega)}{P_{Z}(\omega)} F, \quad \omega \in \Omega .
\end{aligned}
$$

Given that in equilibrium the agent eats the global endowments of the two goods we have $c_{0}^{1}=Y_{0}^{1}, c_{0}^{2}=Y_{0}^{2}, c_{1}^{1}(\omega)=Y_{1}^{1}(\omega)$, and $c_{1}^{2}(\omega)=Y_{1}^{2}(\omega)$, so it follows immediately from the first order conditions that $F=Y_{0}^{1} / \theta, P_{0}^{2}=(1-\theta) Y_{0}^{1} /\left(\theta Y_{0}^{2}\right), P_{1}^{2}(\omega)=(1-\theta) Y_{1}^{1} /\left(\theta Y_{1}^{2}\right)$, and $P_{Z}(\omega)=\beta \pi(\omega) / G^{1}(\omega)$. The price of a state contingent claim against state $\omega$ is the same as in the model with two agents. So is the rate of change of the price of good 2 :

$$
\frac{P_{1}^{2}(\omega)}{P_{0}^{2}}=\frac{G^{1}(\omega)}{G^{2}(\omega)}
$$

The level of the price of good 2 at time 0 is also the same as in the two agent model if the parameter weight of the single agent satisfies

$$
\frac{1-\theta}{\theta}=\frac{\left(1-\theta_{f}\right)(1+\beta)+\left(\theta_{f}-\theta_{d}\right)\left(s_{0}^{1}+\beta \bar{s}_{1}^{1}\right)}{\theta_{f}(1+\beta)+\left(\theta_{d}-\theta_{f}\right)\left(s_{0}^{2}+\beta \bar{s}_{1}^{2}\right)} .
$$

The agent's IMRSs over the individual goods are

$$
\beta \frac{c_{0}^{1}}{c_{1}^{1}(\omega)}=\frac{\beta}{G^{1}(\omega)} \quad \text { and } \quad \beta \frac{c_{0}^{2}}{c_{1}^{2}(\omega)}=\frac{\beta}{G^{2}(\omega)}
$$

which are the same expressions we had for both agents in the two agent model. 